\title{
EMI Shielding and Absorption of Electroconductive Textiles with PANI and PPy Conductive Polymers and Numerical Model Approach
}

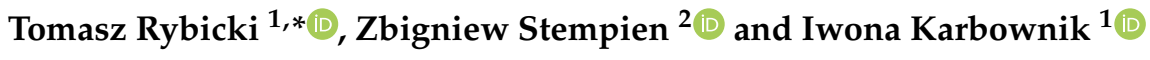 \\ 1 Institute of Automatic Control, Lodz University of Technology, 90-537 Lodz, Poland; ivakabari@gmail.com \\ 2 Faculty of Material Technologies and Textile Design, Lodz University of Technology, 90-924 Lodz, Poland; \\ zbigniew.stempien@p.lodz.pl \\ * Correspondence: trybicki@p.lodz.pl
}

Citation: Rybicki, T.; Stempien, Z.; Karbownik, I. EMI Shielding and Absorption of Electroconductive Textiles with PANI and PPy Conductive Polymers and Numerical Model Approach. Energies 2021, 14, 7746. https://doi.org/10.3390/ en14227746

Academic Editor: Carlos Miguel Costa

Received: 1 October 2021

Accepted: 9 November 2021

Published: 18 November 2021

Publisher's Note: MDPI stays neutral with regard to jurisdictional claims in published maps and institutional affiliations.

Copyright: (c) 2021 by the authors. Licensee MDPI, Basel, Switzerland. This article is an open access article distributed under the terms and conditions of the Creative Commons Attribution (CC BY) license (https:// creativecommons.org/licenses/by/ $4.0 /)$.

\begin{abstract}
The paper presents the results and analysis of interdisciplinary research concerning electromagnetic field shielding, conductive polymers printed on textiles and numerical simulation using the finite element method (FEM). The use of conductive, layered textiles for shielding electromagnetic interference (EMI) has been proposed. After establishing the optimal conditions for deposition of polyaniline (PANI) and polypyrrole (PPy) on polyacrylonitrile (PAN) fabric, conductive composites were made by means of reactive inkjet printing. For this purpose, polyacrylonitrile (PAN) fabrics were coated with polyaniline or polypyrrole, obtained by chemical oxidation of aniline hydrochloride and pyrrole by ammonium peroxydisulfate. The morphology of the obtained coatings was observed using a scanning electron microscope (SEM). The conductive properties (surface resistance) of the fabrics were measured using the four-wire method, and the tests of the effectiveness of electromagnetic shielding were carried out using the waveguide method in the frequency range from 2.5 to $18 \mathrm{GHz}$. The results of experimental shielding effectiveness (SE) tests and numerical simulation showed that the composites of polyacrylonitrile with polyaniline PAN/PANI and polyacrylonitrile with polypyrrole PAN/PPy achieved very good and good EMI shielding efficiency, respectively. Moreover, the obtained measurement results were verified by numerical modeling with the use of FEM-ANSYS HFFS software.
\end{abstract}

Keywords: EMI shielding; conductive polymers; FEM

\section{Introduction}

With the increasing use of electronic products and telecommunication equipment, electromagnetic interference (EMI) has become a major problem, as it reduces the lifetime and efficiency of the instruments. To reduce the impact of electromagnetic radiation, EMI shielding materials are widely investigated. Microwave absorbers, especially radarabsorbing materials (RAMs), are gaining importance thanks to their ability to eliminate electromagnetic wave pollution and to reduce radar signatures. Microwaves have two components, an electric field and a magnetic field, which are perpendicular to each other. Therefore it is necessary to cancel out both components to obtain effective absorption when materials are exposed to microwave radiation. Recently the demand for microwave absorbers in the frequency range of 1 to $20 \mathrm{GHz}$ has increased, because of their dual purpose, electromagnetic interference (EMI) shielding efficiency (SE) and counteracting to radar detection. An ideal microwave-absorbing material possesses such advantages as thinness, low density, light weight, low cost, wide bandwidth, and design flexibility [1-3]. Radar-absorbing materials (RAMs) are widely used in commercial as well as military applications [4]. The best RAMs exhibit microwave-absorbing properties over a wide frequency range [5]. The demand for inexpensive electromagnetic interference (EMI) shielding materials has led to a great deal of research into the shielding properties of polymer composites 
and conductive polymers (as alternatives to metallic materials) [6-15]. Coating fabrics with conductive polymers to create shielding materials has the afore-mentioned advantages, including low cost of obtaining them, and besides, these materials are flexible and light. Both polyaniline and polypyrrole are materials with high electromagnetic radiation shielding efficiency [16-27]. Polyaniline (PANI) has been known since the nineteenth century and is one of the best-studied electrically conductive polymers. The polyaniline chain consists of oxidized and reduced segments. The PANI oxidized form shows electrical conductivity. Its specific conductivity is in the range of $101-104 \mathrm{~S} / \mathrm{cm}$. Polyaniline is also used in protective coatings, such as an antistatic material, a component of radar adsorbing varnishes, PLED displays (polymer light-emitting diodes) and can be a catalyst in the processes of heterogeneous catalysis. Polyaniline (PANI) is perhaps the most versatile because it is easy and inexpensive to prepare and has desirable properties such as thermal and chemical stability, low specific mass, controllable conductivity and high conductivity at microwave frequencies [28-30].

Another very important conductive polymer due to its properties is polypyrrole (PPy). It is stable both in atmospheric conditions and the aquatic environment, and it is also biocompatible. PPy has a specific conductivity of $102 \mathrm{~S} / \mathrm{cm}$. It is used in batteries, accumulators, as a conductive component of heating elements and also as a metal corrosion inhibitor.

There are different ways of applying conductive polymers to textiles. One common approach route is to apply dispersions or powder of fully prepared conductive polymers as coatings. These approaches usually result in rather low conducting materials. An interesting alternative is to create conductive polymers by polymerizing monomers on the textile. PANI and PPy nanocomposites in textiles can also be superior microwave absorbers because of their light weight, flexible processability and variable conductivity [24,25,31-35]. Methods for in situ polymerization (by oxidation) are well known in this context. Essentially, the oxidative polymerization of a fabric may follow three procedures: Application of the oxidant to the textile followed by addition of monomer, application of monomer followed by oxidizing agent and application of a polymerizable mixture of monomer and oxidant $[25,36]$. The inkjet printing technique is an interesting and versatile method for controlled deposition of functional materials with suitable geometry on various substrates [37]. It does not require any contact between the deposition system and the substrate. The only constraint of this technique is the requirement for fluids with suitable rheological parameters [38-40]. PANI and PPy nanodispersions show a great deal of promise for shielding applications, given that they are inkjet-printable and facilitate the patterning of conducting polymers directly on the substrate [31,40].

Currently, model studies are increasingly used as a research method in the field of shielding effectiveness of various materials, including textiles. Literature reports [41-49] show two main directions of development of such research: various analytical modeling processes and numerical modeling.

Analytical models try to describe the phenomenon of electromagnetic wave shielding on the basis of known physical laws and consequently lead to parametric mathematical relationships [41-44]. The modeling process in this case comes down to the parameterization of mathematical equations based on the knowledge obtained from the research of real objects and measurements. Analytical modeling methods are fast and effective; however, they should be verified numerically or experimentally [45]. However, the process of numerical modeling is associated with the huge development of computer science and information technology in the recent years. The modeling process is based on physical phenomena and mathematical relationships, but the modeling process comes down to a faithful reproduction of a phenomenon or experiment in a virtual measurement environment. From the point of view of electromagnetic phenomena modeling, the most frequently used methods of discretization of Maxwell's equations are: the finite difference time domain method (FDTD) (preferred for solutions in time domain) [46,47], the finite 
element method (FEM) (preferred in the frequency domain) $[45,48]$ and the method of boundary elements (moments) [49].

The study involved in-situ polymerization of polyaniline (PANI) and in-situ polymerization of polypyrrole (PPy) on polyacrylonitrile (PAN) fabrics using the reactive inkjet printing technique [31]. Polyaniline- and polypyrrole-coated conducting fabrics were obtained by chemical oxidation of aniline hydrochloride or pyrrole by ammonium peroxydisulfate on polyacrylonitrile (PAN). The morphology of the coatings was observed by scanning electron microscopy (SEM). The electrical properties of the fabric samples were measured by the van der Pauw method. The structures of the PAN with polyaniline printing and the PAN with polypyrrole printing were characterized and assessed in terms of their effectiveness of electromagnetic shielding, determining the transmission and reflection characteristics. These characteristics were defined in the frequency range from 2.5 to $18 \mathrm{GHz}$. The results showed that PANI/PAN and PPy/PAN composites achieved very good and moderate EMI shielding effectiveness, respectively. The results of transmission and reflection of the electromagnetic wave from the tested shielding sample were compared with analogous characteristics obtained numerically using the FEM ANSYS HFSS software package.

\section{Materials and Methods}

\subsection{Materials}

Aniline hydrochloride 97\% was obtained from POCh, Poland, and Pyrrole 98\% was supplied by Sigma-Aldrich (St. Louis, MO, USA) and used as supplied. Ammonium peroxydisulfate was from Chempur, Poland and used without purification. Commercial polyacrylonitrile fabric was used for printing. The characteristics of the fabric samples were as follows: weave type-2/1 twill, weight $220 \mathrm{~g} / \mathrm{m}^{2}$, warp density 24 yarns $/ \mathrm{cm}$, weft density 17 yarns $/ \mathrm{cm}$. Structural parameters of substrate fabrics were determined using standard test methods, respectively: mass per unit area $\left(\mathrm{g} / \mathrm{m}^{2}\right)$ according to EN 12127 [50]; number of threads per unit length according to EN 1049-2 [51]. The amount of coating deposit $\left(\mathrm{g} / \mathrm{m}^{2}\right)$ for coated samples was evaluated by measuring mass per unit area of the manufactured coated samples and subtracting the value of mass per unit area of a control sample.

\subsection{Methods}

The following subsections present the methods used in the experimental part of the paper. The methods involved in obtaining the shielding samples and their characterization were described. Among the measurement methods, experimental methods, such as scanning electron microscope measurements, surface resistivity and transmittance and reflectance measurements of the samples; and simulation methods, such as, geometry generation and electromagnetic simulations using FEM, were included.

\subsubsection{Formation of Material for Electrical Conductivity Tests and Electromagnetic Wave Attenuation}

The research material was made by depositing PANI or PPy conductive layers on PAN fabrics. The formation of conductive layers was achieved by oxidizing inkjet printing of aniline hydrochloride or pyrrole with ammonium peroxodisulfate, which was described in detail in [31]. In order to make the printed layers, a prototype of a digital inkjet printer was used [31]. Electrically conductive layers were applied line by line on the fabric surface so that one nozzle sprayed the selected pattern line with an aqueous solution of aniline hydrochloride or pyrrole, and then the other nozzle sprayed the same pattern line with the aqueous solution of ammonium peroxodisulfate. According to the afore-mentioned reactive inkjet printing method, the material was produced by depositing PANI or PPy layers on a PAN fabric. The oxidant:aniline hydrochloride molar ratio was 1.2:1 and the oxidant:pyrrole was 1:1. The fabric samples were printed at a constant concentration of 
$0.8 \mathrm{M}$ aniline hydrochloride and a constant concentration of pyrrole of $0.8 \mathrm{M}$ in each of the printed layers.

\subsubsection{Scanning Electron Microscope Measurements}

Scanning electron microscopy was used to determine PANI or PPy morphology and assess the distribution of PANI or PPy on the textile surface. The material was characterized by SEM with field emission VEGA3 (TESCAN, Brno, Czech Republic).

\subsubsection{Measurements of Surface Resistivity}

Figure 1 presents the idea of testing the surface resistance of textile samples with conductive polymers PANI and PPy. The measurement method uses the approach proposed by van der Pauw [52], adapted to textiles [53,54]. Four silver-coated cylindrical electrodes with a diameter of $2 \mathrm{~mm}$ were used, placed in the corners of the tested sample. The distance between the electrodes was $28 \mathrm{~mm}$ and the pressing force of each was $1 \mathrm{~N}$. An Agilent 34410A power supply was used as the DC source, while the Picotest M3500A was used as a precision voltmeter. Four different measurements were made by rotating the sample $90^{\circ}$.

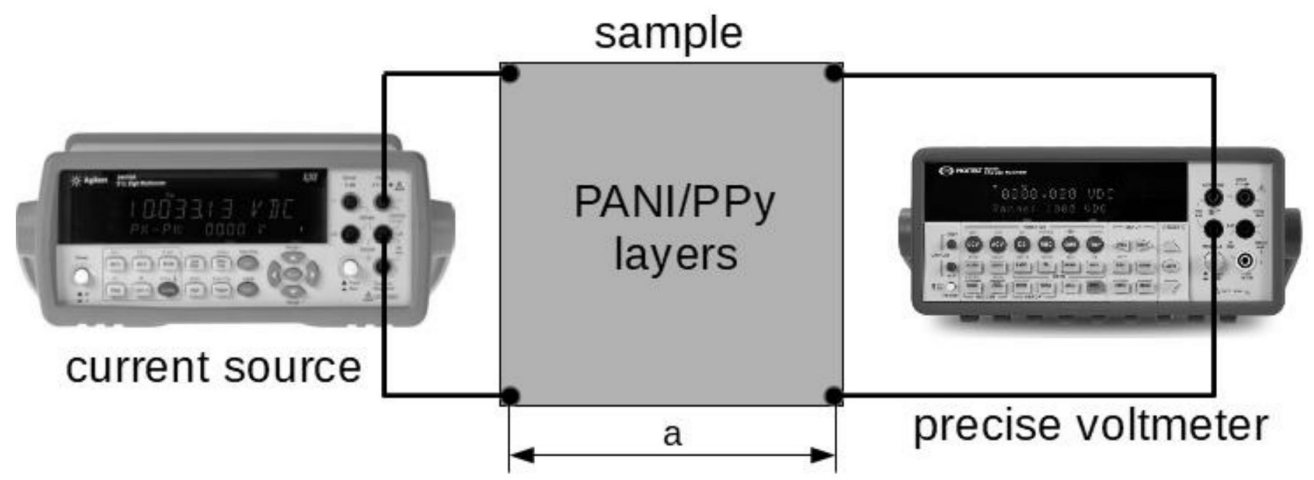

Figure 1. Stand for testing the surface resistance of textile samples with conductive polymers PANI and PPy.

\subsubsection{Measurement of the Effectiveness of Electromagnetic Interference Shielding}

The effectiveness of electromagnetic interference shielding by textile samples with conductive polymers was measured with the use of the waveguide method in the TE10 mode in the frequency range from 2.5 to $18.0 \mathrm{GHz}$. Figure 2 shows a simplified diagram of the test stand using the waveguide applicator method. The measuring stand enables the independent determination of the transmittance and reflectance coefficients in [dB] and has been described in detail in our previous works [43,55]. Due to the wide range of tested frequencies, five measurement sub-ranges using different sets of waveguides were used:

WR-284 (2.5-3.5 GHz),

WR-187 (3.5-5.0 GHz),

WR-137 (5.0-8.0 GHz),

WR-90 (8.0-13.0 GHz),

WR-62 (13.0-18.0 GHz).

As a result of measurements, one acquires:

- The transmittance of the sample (in $\mathrm{dB}$ ) $-T_{1}$ that is defined as the logarithmic ratio of power of electromagnetic wave measured behind the tested sample to the incident power of electromagnetic wave on its surface:

$$
T_{1}=10 \log (T) \text {, in } \mathrm{dB}
$$


- The reflectance of the sample (in $\mathrm{dB}$ ) $-R_{1}$ defined as the logarithmic ratio of the signal reflected from the sample tested to the power of incident radiation on its surface, which can be expressed as:

$$
R_{1}=10 \log (R), \text { in } \mathrm{dB}
$$

where:

$T$-transmittance of the sample, $T=P_{2} / P_{1}$;

$R$-reflectance of the sample, $R=P_{R} / P_{1}$;

$P_{1}$-incident power on the tested sample, $\mathrm{mW}$;

$\mathrm{P}_{2}$-measured power behind the tested sample, $\mathrm{mW}$;

$P_{R}$ - power reflected from the tested sample, $\mathrm{mW}$.

\section{synthesizer sweeper}

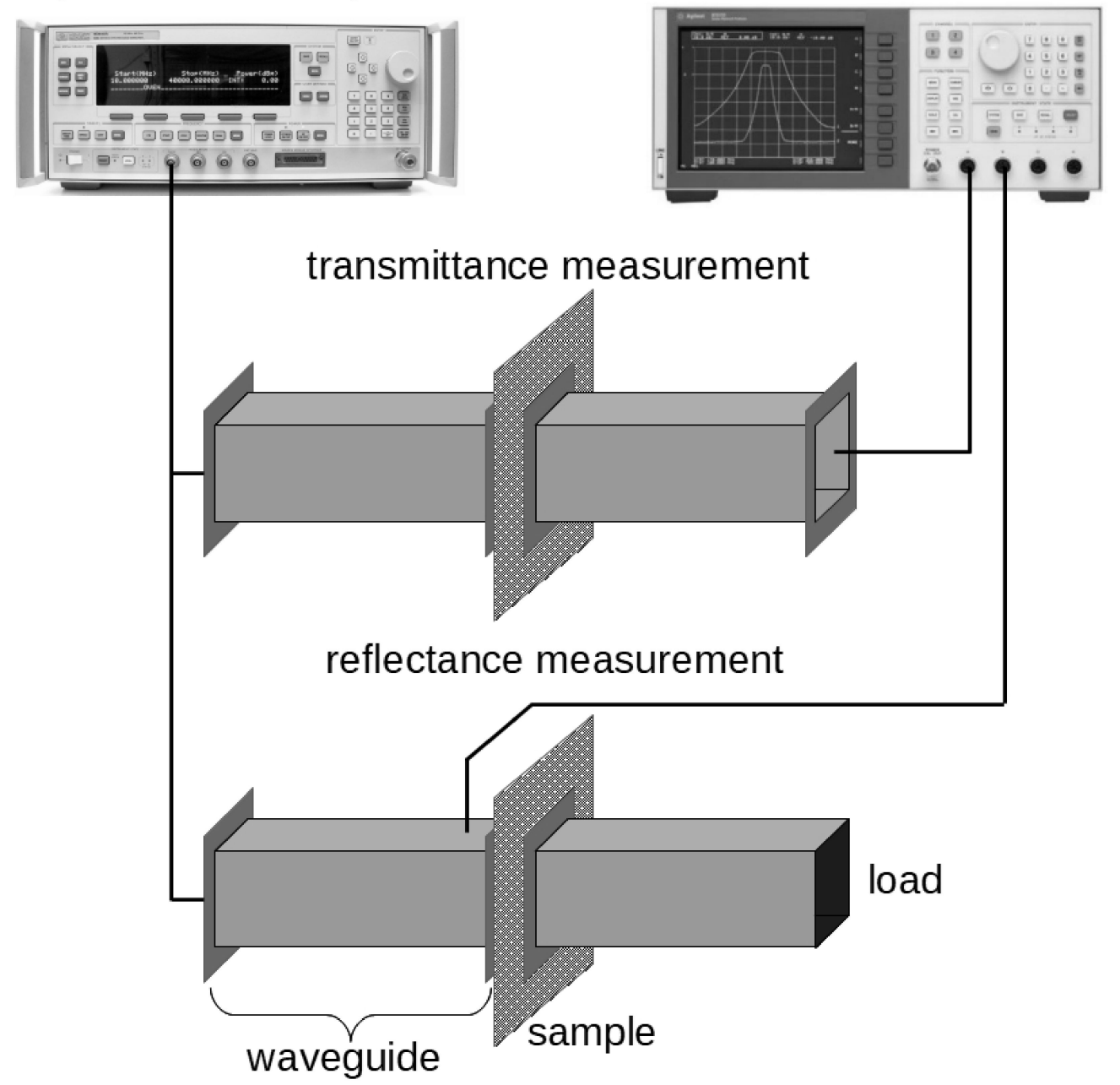

Figure 2. Stand for the independent determination of the transmittance and reflectance of the sample.

A simplified analytical model of the considered shielding phenomenon from the point of view of the transmission $(t)$ and reflection $(r)$ coefficients in the TE10 mode of the waveguide, taking into account only the conductivity of the sample and the dispersion of electromagnetic wave in rectangular waveguide, can be expressed as [56-58]:

$$
t=\frac{2 D}{Z_{0} \sigma+2 D} \quad r=-\frac{Z_{0} \sigma}{Z_{0} \sigma+2 D}
$$

where: 
$t$-transmission coefficient, $r$-reflection coefficient, $\sigma$-conductivity of the sample, $Z_{0}$-the wave impedance of plane waves in free space, $Z_{0}=\sqrt{\frac{\mu_{0}}{\epsilon_{0}}}$, (where $\epsilon_{0}$ is the permittivity constant in free space and $\mu_{0}$ is the permeability constant in free space. $\epsilon_{0}$ is equal to approximately $8.85 \cdot 10^{-12} \mathrm{~F} / \mathrm{m}$ and $\mu_{0}$ equals $4 \pi \cdot 10^{-7} \mathrm{H} / \mathrm{m}$.), $Z_{0} \approx 377 \Omega$.

$D=\sqrt{1-\left(\frac{f_{c}}{f}\right)^{2}}$-dispersion of electromagnetic wave in rectangular waveguide, $f$-microwave frequency, $f_{c}$-rectangular waveguide cut-off frequency in TE10 mode.

It is well known [59] that $R=r^{2}$ and $T=t^{2}$, so the absorption coefficient should be determined on the basis of the energy conservation law:

$$
A=1-R-T
$$

\subsubsection{Numerical Modeling of Electromagnetic Interference Shielding Effectiveness}

The simulated verification of the obtained experimental results of the shielding efficiency in the form of transmittance and reflectance coefficients was carried out in the ANSYS HFFS software environment, using the finite element method [48]. According to Figure 2, a virtual measuring environment was modeled in Ansys by recreating the geometry of the actual measuring stand consisting of the following waveguides: WR-284, WR-187, WR-137, WR-90, WR-62 in the TE10 mode, in the appropriate frequency ranges. The tested textile samples with PANI and PPy layers were placed in the center of the waveguides in the form of a barrier of appropriate thickness, and appropriate material parameters were assigned to them. The cross section of the exemplary WR-137 waveguide with the results of the electric field distribution in front of and behind the shielding sample and the whole set of simulation results in the tested frequency ranges $(2.5-18.0 \mathrm{GHz})$ in the form of transmittance and reflectance from the shielding samples were shown in Section 3.4. Using TexGen (open source) software [60,61], virtual models of shielding material samples were created, trying to faithfully reproduce the structure of the weave and material properties. The parameters influencing the adjustment of the results of the experimental and model data were the equivalent thickness of the thread $(0.35 \mathrm{~mm})$ and polymer coating used, conductivity of the polymer coating, material parameters of PANI and PPy polymers. Figure 3 shows the process of creating (Figure 3a) and an example of (Figure 3b) a numerical model of the fabric created. The characteristics of the fabric samples were as follows: weave type-twill 2/1, warp density 24 yarns/cm, and weft density 17 yarns $/ \mathrm{cm}$.

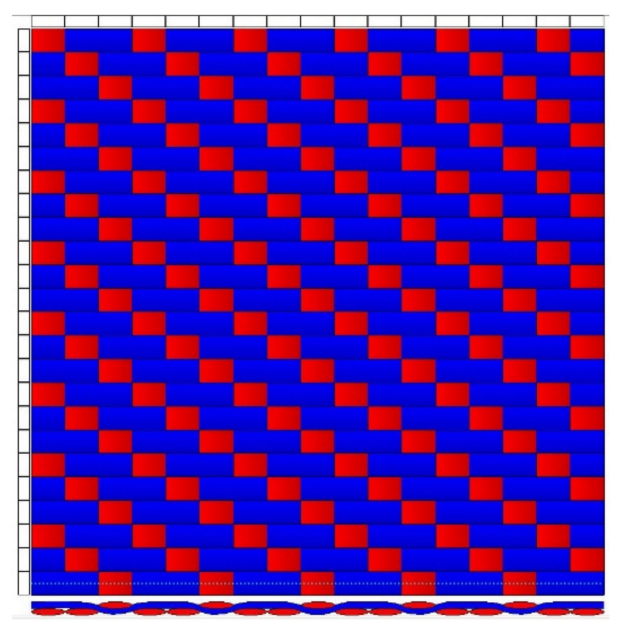

(a)

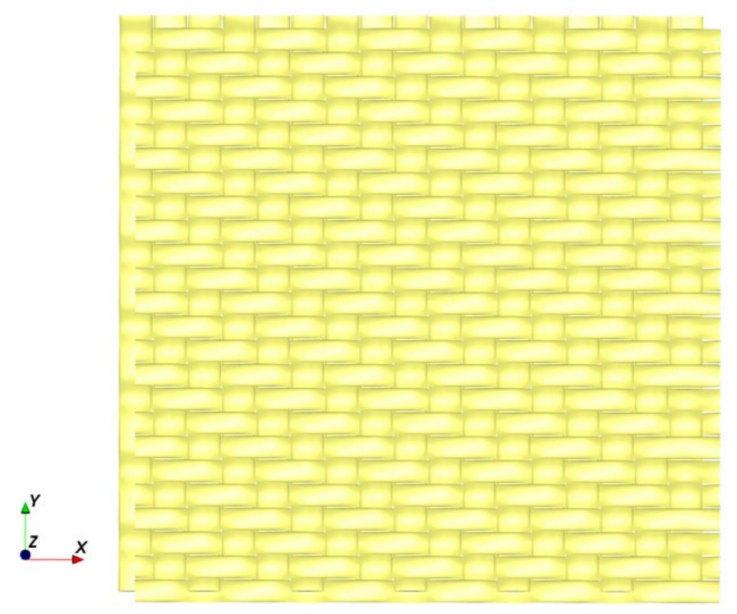

(b)

Figure 3. (a) The process of creating a $2 / 1$ twill weave in the TexGen program; (b) final appearance of the numerical model $2 / 1$ twill in the TexGen $[60,61]$ program. 


\section{Results and Discussion}

\subsection{Morphological Characterization}

For morphological characterization, as previously stated, SEM was employed to view and analyze the samples. Figures 4-6 show the appearance of PAN surfaces printed one, three and five times with PANI and PPy conductive polymers by reactive inkjet printing. Figure 4 illustrates the appearance of one layer of conductive polymers on a PAN fabric.

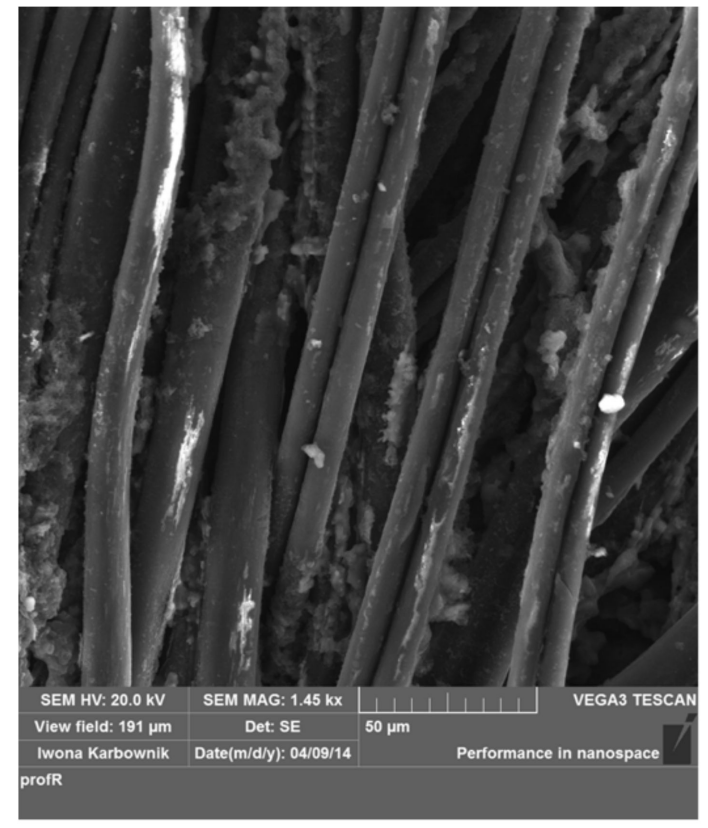

(a)

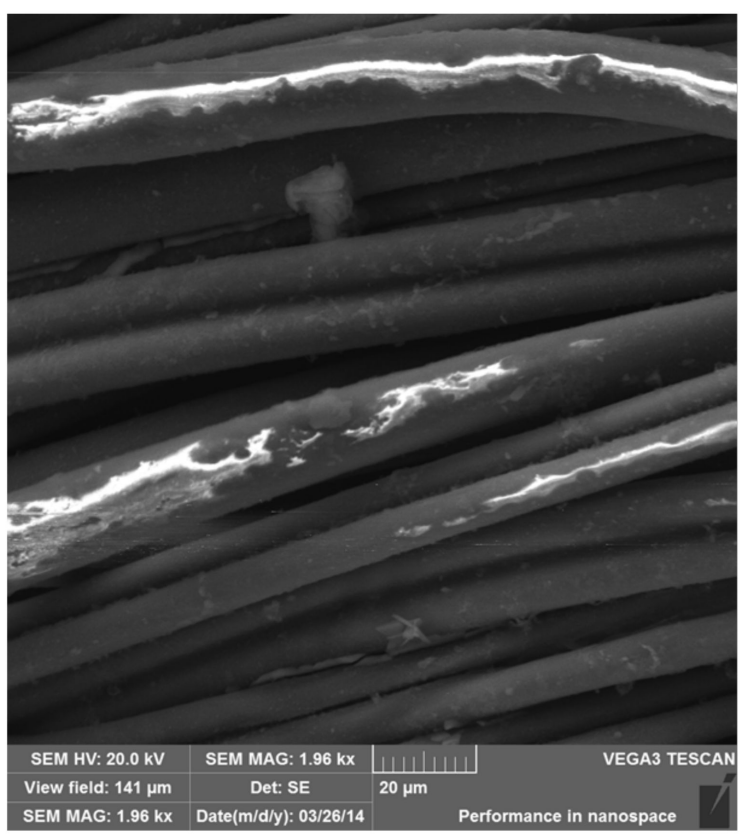

(b)

Figure 4. SEM images of: (a) One layer of PANI; (b) one layer of PPy inkjet printed on PAN substrate.

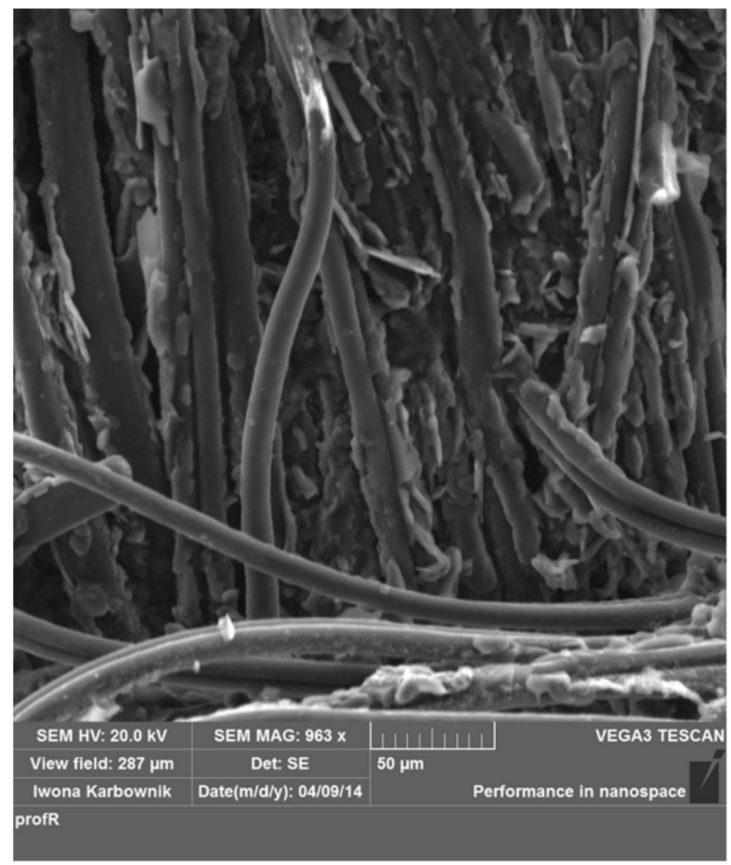

(a)

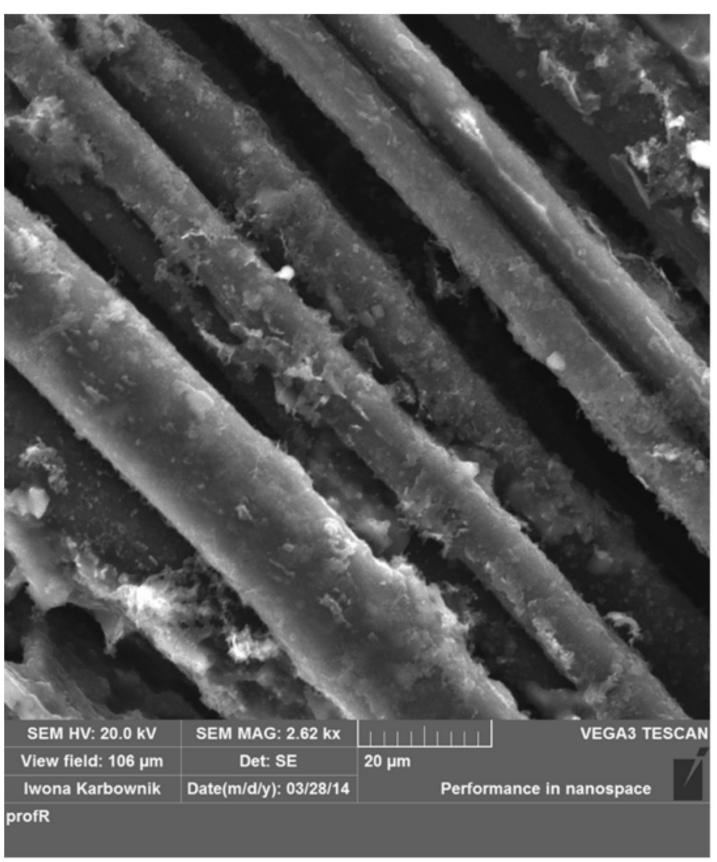

(b)

Figure 5. SEM images of: (a) Three layers of PANI; (b) three layers of PPy inkjet printed on PAN substrate. 


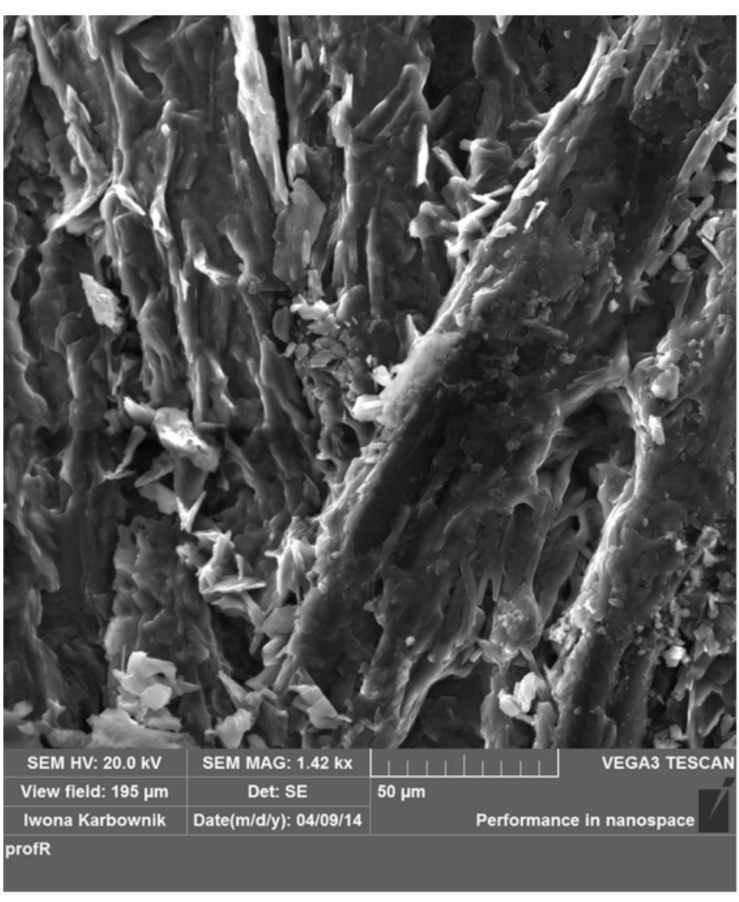

(a)

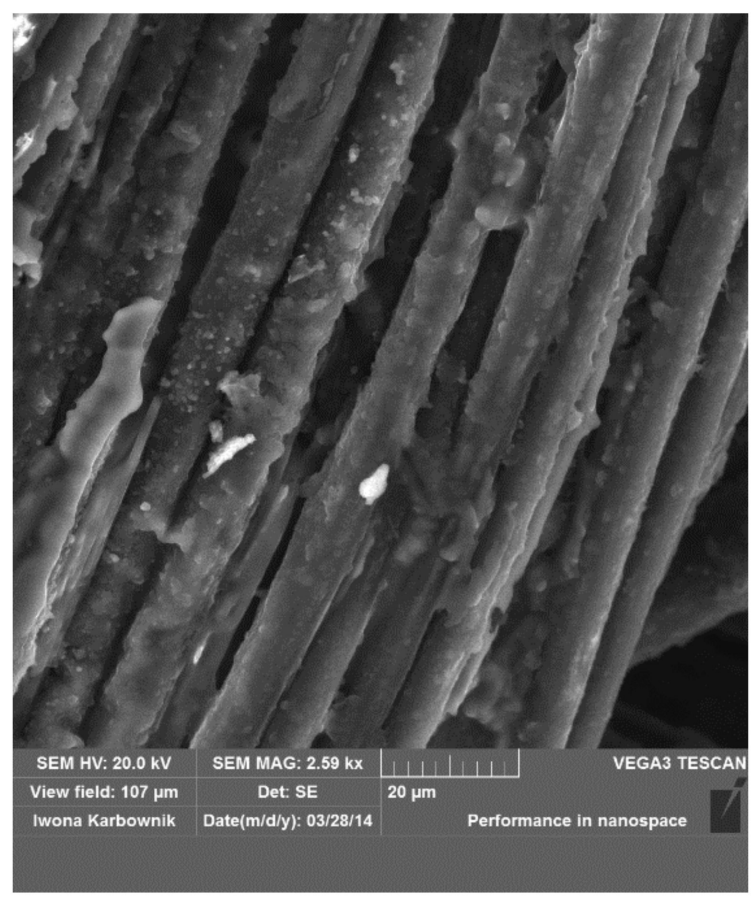

(b)

Figure 6. SEM images of: (a) Five layers of PANI; (b) five layers of PPy inkjet printed on PAN substrate.

Figure 5 shows the SEM image of the PAN substrate surface coated with three layers of PANI and the PAN substrate surface coated with three layers of PPy. From the visual observation, it is observed that there is a considerable amount of PANI and PPy particles on the sample surfaces.

SEM image, as shown in Figure 6, of the five layers of coating of PANI on PAN substrate and five layers of coating of PPy on PAN substrate, illustrates a high amount of PANI and PPy particles on the surface.

Subsequent polymer layers (PANI and PPy) were obtained by combining monomer molecules in the presence of a solvent which was being evaporated during drying [31].

The rheological parameters of the solutions were selected during the processing (the components of the solutions were chosen to give viscosity not exceeding $0.005 \mathrm{~Pa} \cdot \mathrm{s}$, surface tension of $35 \mathrm{mN} / \mathrm{m}-40 \mathrm{nmN} / \mathrm{m}$, density $0.9855 \mathrm{~g} / \mathrm{dm}^{3}$ ) (i.e., during the application of the polymer to the fibrous material), which made it possible to carry out the process of applying polymers and influenced the increase in the rate of obtaining composites.

On the surface of the fibrous product (PAN fabric), the structure of which is shown in Figure 3 and the appearance of the real surface can be observed in the SEM photos (Figures 4-6), it was difficult to apply a continuous layer of reactive inkjet printing polymer. This is especially visible in the pictures showing one-layer, three-layer and five-layer PPy deposition (Figures $4 b, 5 b$ and $6 b$ ).

\subsection{PANI Surface Weight and Layer Thickness vs. Number of Layers}

Table 1 shows the characteristics of PANI and PPy layers printed on a PAN textile substrate. The surface weight reflects the amount of polymer used in the production of the layers per $1 \mathrm{~m}^{2}$ of the surface. The thickness of the printed layer on textiles is defined as the so-called equivalent, normalized thickness. In the case of textile substrates, it is very difficult to measure the thickness of the printed layers because the ink polymer penetrates internally some or all of the fabric structure and after drying the polymeric material is distributed in the space between the fibers. Table 1 shows the equivalent normalized print thickness calculated from the polymer density. The assumed density for PANI was $1.32 \mathrm{~g} / \mathrm{cm}^{3}$, while for PPy it was $1.50 \mathrm{~g} / \mathrm{cm}^{3}$, respectively $[62,63]$. 
Table 1. Characteristics of PAN samples vs. number of PANI or PPy layers.

\begin{tabular}{cccc}
\hline Sample Type & Number of Layers & $\begin{array}{c}\text { Surface Weight, } \\
\mathbf{g} / \mathbf{m}^{\mathbf{2}}\end{array}$ & $\begin{array}{c}\text { Equivalent Thickness } \\
\boldsymbol{\mu} \mathbf{m}\end{array}$ \\
\hline \multirow{3}{*}{ PAN/PANI } & 1 & 16.4 & 12.4 \\
\cline { 2 - 4 } & 3 & 60.1 & 45.2 \\
\hline \multirow{2}{*}{ PAN/PPy } & 5 & 105.9 & 79.7 \\
\cline { 2 - 4 } & 1 & 13.5 & 9.0 \\
\hline & 3 & 47.8 & 31.8 \\
\hline
\end{tabular}

\subsection{Surface Resistance-PANI and PPy Surfaces Weight vs. Number of Layers}

Table 2 shows the average values (from four measurements) of the surface resistance of PANI and PPy layers on PAN fabrics depending on their number. As you can see, with an increase in the number of layers, a rapid and non-linear decrease in surface resistance occurs - up to $20 \Omega$ /sq for PAN/PANI and up to $96 \Omega /$ sq for PAN/PPy. The surface resistance for PANI layers is much lower than for the same number of PPy layers, which is the result of the difference in the specific conductivity of both polymers.

Table 2. Surface resistance of PAN/PANI and PAN/PPy samples as a function of the number of inkjet-printed polymer layers.

\begin{tabular}{cccccccc}
\hline Sample Type & \multicolumn{3}{c}{ PAN/PANI } & \multicolumn{3}{c}{ PAN/PPy } \\
\hline $\begin{array}{c}\text { Numer of conductive } \\
\text { polymer layers }\end{array}$ & 1 & 3 & 5 & 1 & 3 & 5 \\
\hline Surface resistance, $\Omega$ /sq. & 127 & 33 & 20 & 380 & 165 & 96 \\
\hline
\end{tabular}

\subsection{Effectiveness of Electromagnetic Shielding}

Figures 7 and 8 show the results of measurements of the electromagnetic wave transmittance and reflectance from textile shielding samples using inkjet-printed layers of PANI and PPy conductive polymers. The measurements were carried out using the waveguide method in the TE10 mode, in the frequency range from 2.5 to $18 \mathrm{GHz}$. The transmittance (Formula (1)) presented in Figure 7 provides information on the level of protection against electromagnetic radiation. It is related to the level of shielding efficiency (SE) widely cited in the literature [64], which is defined as the reciprocal of the transmission factor:

$$
S E=-T_{1}=-10 \log (T)=10 \log (1 / T)=10 \log \left(P_{1} / P_{2}\right), \text { in } \mathrm{dB}
$$

or, using the intensities of electric field in front of and behind the shield:

$$
S E_{E}=20 \log \left(E_{1} / E_{2}\right) \text {, in } \mathrm{dB}
$$

where $E_{1}, E_{2}$ are the intensities of electric field in front of and behind the shield, respectively.

It is desirable that the shielding material has a low value of transmittance (i.e., by Formula (5) a high value of the shielding effectiveness). Document [65] gives the requirements for shielding effectiveness for textile shielding materials in two classes: class I-professional use and class II-general use. The results of the transmission coefficient/screening efficiency, presented in Figure 7, can be related to the requirements of class II (general use) of the document [65]. This class divides the shielding effectiveness into five degrees (five grades): excellent- $\mathrm{SE}>30 \mathrm{~dB}$; very good-30 dB $\geq \mathrm{SE} \geq 20 \mathrm{~dB}$; good-20 dB $\geq \mathrm{SE} \geq 10 \mathrm{~dB}$; moderate- $10 \mathrm{~dB} \geq \mathrm{SE} \geq 7 \mathrm{~dB}$ and fair $-7 \mathrm{~dB} \geq \mathrm{SE} \geq 5 \mathrm{~dB}$. As can be seen from Figure 7, the five-layer PANI coating meets the requirements of class II as very good, while the three-layer and single-layer coatings meet the requirements of good and fair, 
respectively. PPy coated samples are characterized by worse shielding effectiveness. Only five layers of PPy coverage meets the requirements of class II moderate. The three- and single-layer PPy coatings are characterized by SE at a level of less than $5 \mathrm{~dB}$. The great advantage of the presented characteristics of transmittance, visible in Figure 7, is their parallelism to the frequency axis, which proves the independence of the SE coefficient from the frequency in the tested range from 2.5 to $18 \mathrm{GHz}$.

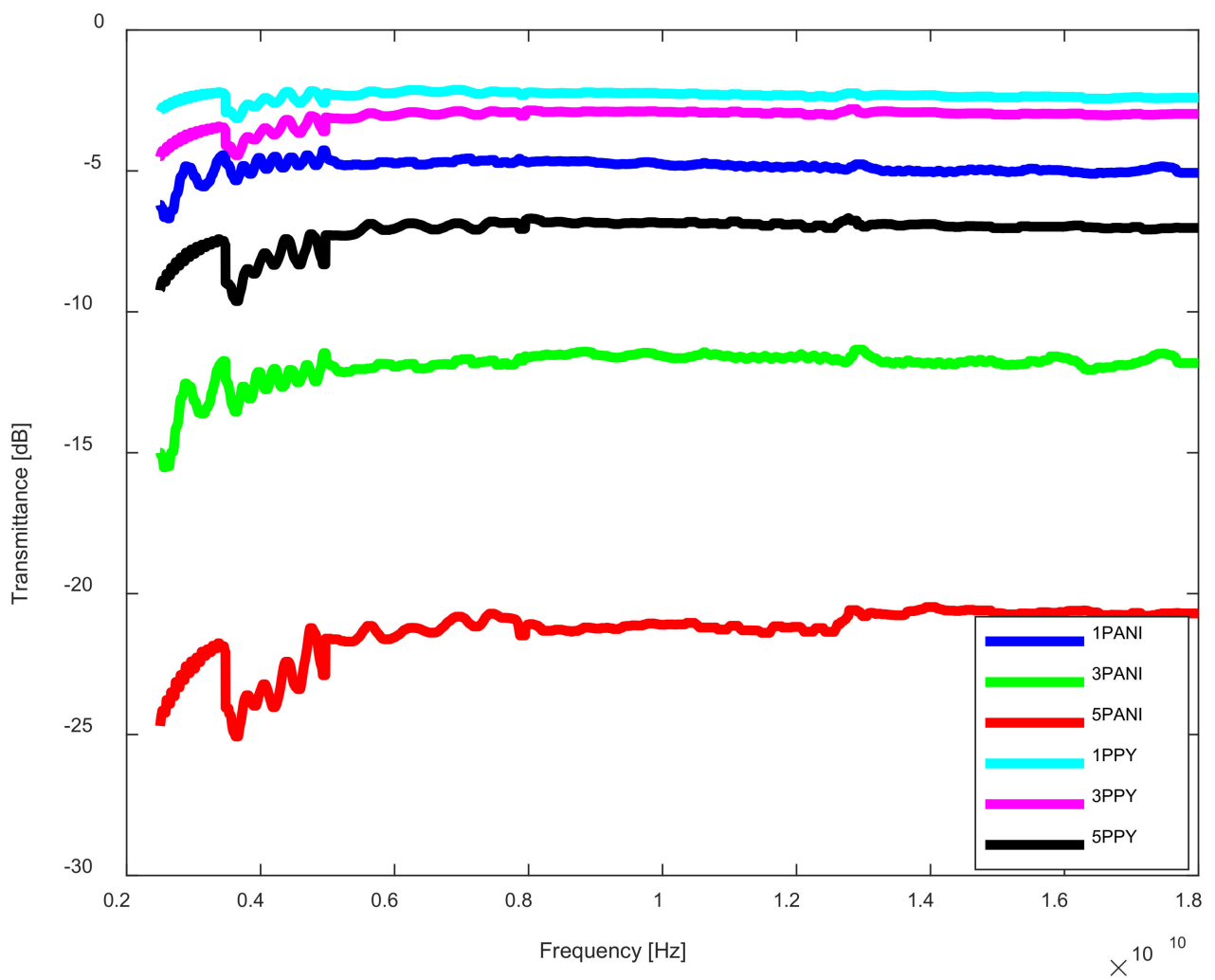

Figure 7. Results of measurements of transmittance in the tested frequency range from 2.5 to $18 \mathrm{GHz}$ for textile samples printed with PANI and PPy conductive polymers.

The waveforms of the electromagnetic wave reflection from the shielding material presented in Figure 8 allow determining the level of reflection loss for each of the samples. They show that the five- and three-layer samples covered with PANI and the five-layer samples covered with PPy are showing the most reflective character. However, one- and three-layer samples covered with PPy show the lowest reflection, which is due to the fact that these samples are also the least shielding samples and the electromagnetic wave passes through them.

In order to make a better distinction between the main shielding factors (reflection, absorption) of each sample, the transmittance (SE) and the reflectance coefficient were converted from $\mathrm{dB}$ to percentages and using Formula (4), and the percentage insertion loss coefficient was determined. The results for the mean values in the range of 2.5 to $18 \mathrm{GHz}$ are presented in Table 3. This table allows the determination of the dominant shielding component for a given sample with the required value of the SE coefficient. It can be seen that the samples with five layers of PANI coverage, characterized by the highest average value of the SE coefficient $(22 \mathrm{~dB})$, achieved this value of SE thanks to almost $80 \%$ reflection and almost $20 \%$ absorption of the electromagnetic wave. Samples with lower SE values, such as three-layers of PANI coverage and five-layers of PPy coverage, are characterized by higher $(41.2 \%$ and $51.8 \%$ ) values of the attenuation coefficient; however, the level of shielding effectiveness may not be sufficient for some applications. 


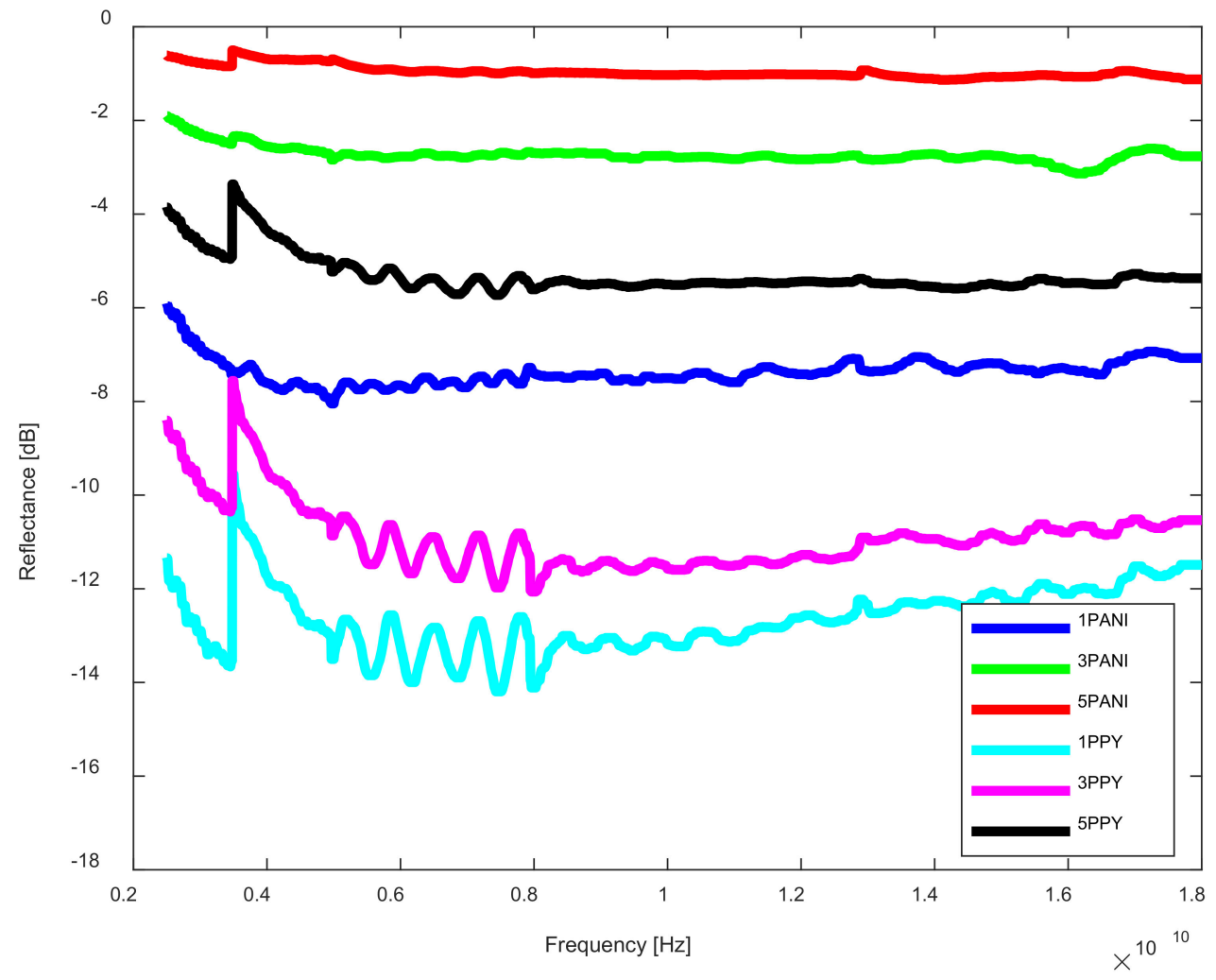

Figure 8. Results of measurements of reflectance in the tested frequency range from 2.5 to $18 \mathrm{GHz}$ for textile samples inkjet printed with conductive polymers PANI and PPy.

Table 3. Average values of shielding efficiency, transmission, reflection and absorption in $\mathrm{dB}$ and percentages.

\begin{tabular}{cccccc}
\hline $\begin{array}{c}\text { Sample } \\
\text { Number }\end{array}$ & $\begin{array}{c}\text { SE (1/Trans- } \\
\text { mittance) } \\
{[\mathbf{d B}]}\end{array}$ & $\begin{array}{c}\text { Reflectance } \\
{[\mathbf{d B}]}\end{array}$ & $\begin{array}{c}\text { Transmission } \\
\text { Coefficient } \\
{[\%]}\end{array}$ & $\begin{array}{c}\text { Reflection } \\
\text { Coefficient } \\
{[\%]}\end{array}$ & $\begin{array}{c}\text { Absorption } \\
\text { Coefficient } \\
{[\%]}\end{array}$ \\
\hline 1 w PANI & 5.00 & -7.50 & 31.62 & 17.78 & 50.59 \\
\hline 3 w PANI & 12.00 & -2.80 & 6.31 & 52.48 & 41.21 \\
\hline 5 w PANI & 22.00 & -1.00 & 0.63 & 79.43 & 19.94 \\
\hline 1 w PPy & 2.25 & -13.00 & 59.57 & 5.01 & 35.42 \\
\hline 3 w PPy & 3.00 & -11.50 & 50.12 & 7.08 & 42.80 \\
\hline 5 w PPy & 7.00 & -5.50 & 19.95 & 28.18 & 51.86 \\
\hline
\end{tabular}

To better illustrate the percentage components of shielding from Table 3 for all the PANI and PPy samples, their comparison was made on the bar charts shown in Figures 9 and 10. The analysis of these graphs should be performed together with the assumed level of shielding effectiveness.

Referring to Equation (6) and based upon the ANSYS HFSS simulation software, Figures 11 and 12 show the intensities of electric field distribution in the WR-137 waveguide fragment for the frequency of $6 \mathrm{GHz}$. The tests were carried out using a virtual measurement environment created in connection with the diagram shown in Figure 2 and with the shield model taken from Figure 3. The selected parts of the waveguide show the field distribution just before (at the bottom of Figures 11 and 12) and just behind (at the top of Figures 11 and 12) the waveguide barrier, which is the tested sample of the shielding material. A significant electric field suppression is visible, which increases with the number 
of conducting polymer layers. The damping of electric field is also greater for polyaniline (Figure 11) compared to polypyrrole (Figure 12).

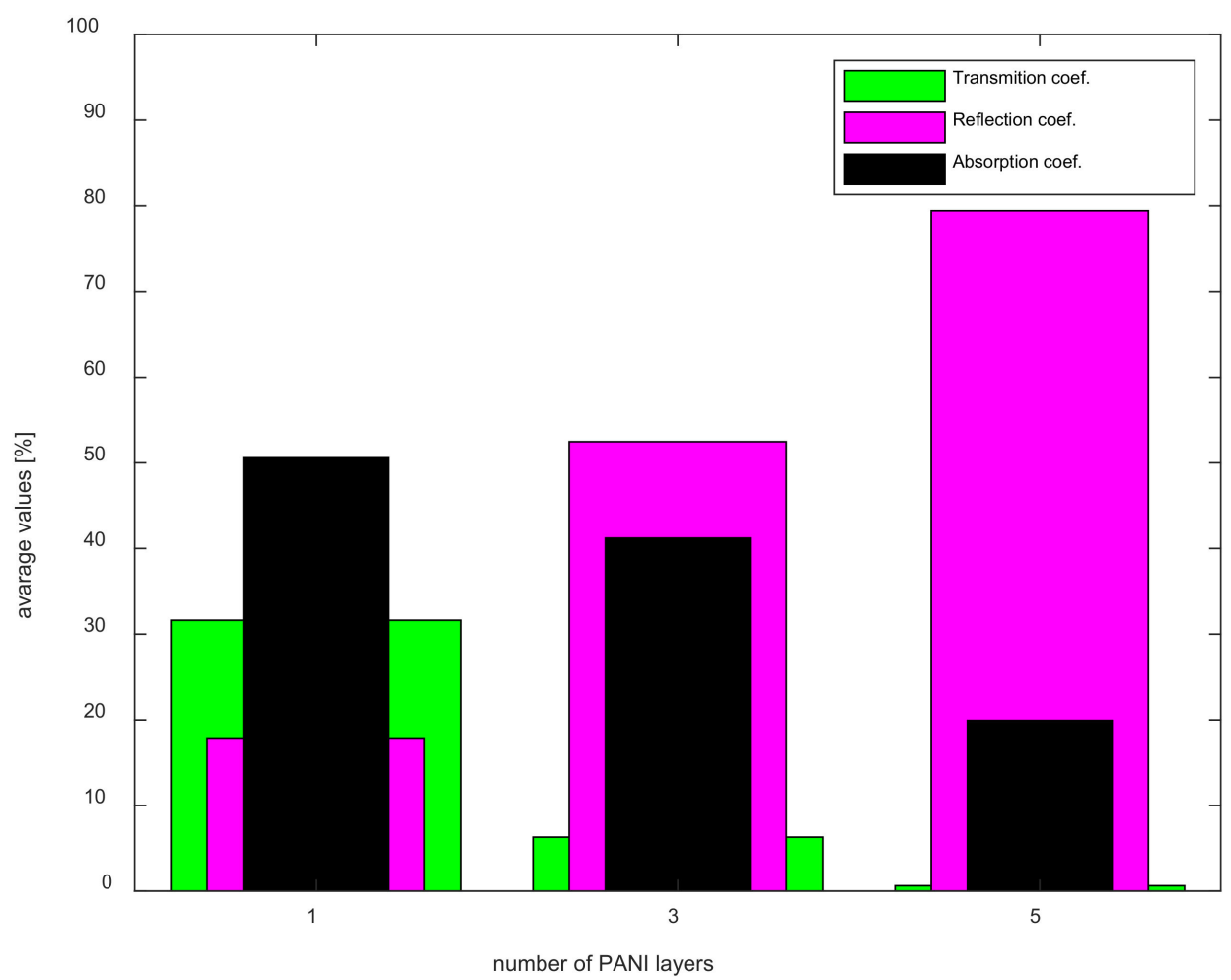

Figure 9. Percentage components of shielding for samples with PANI layers.

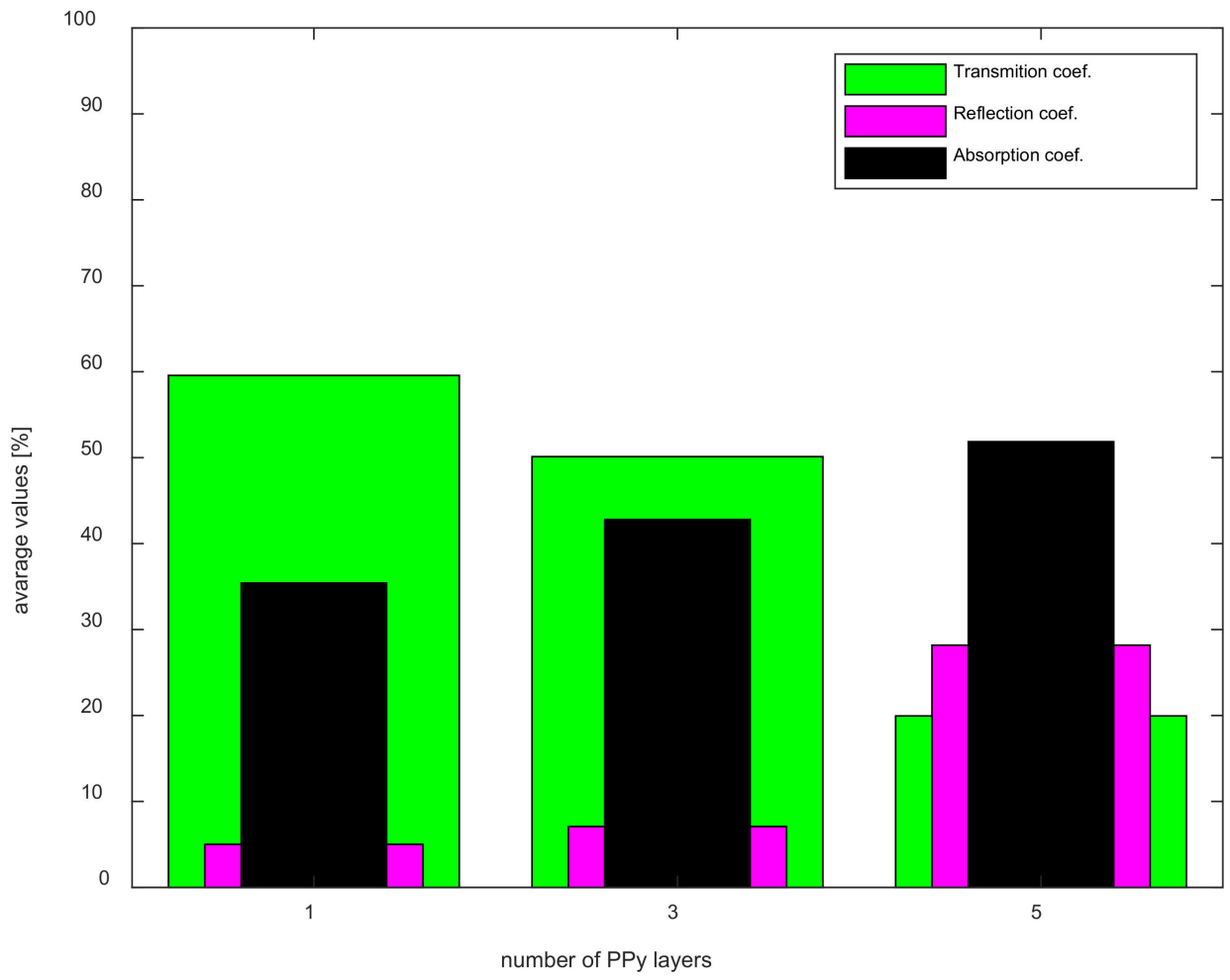

Figure 10. Percentage components of shielding for samples with PPy layers. 
A



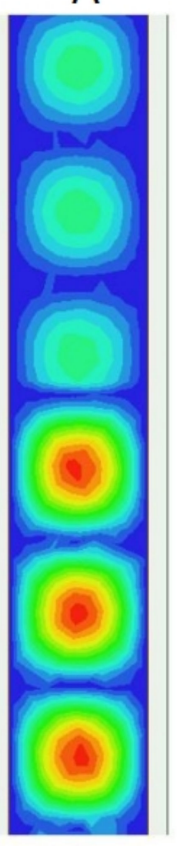

B

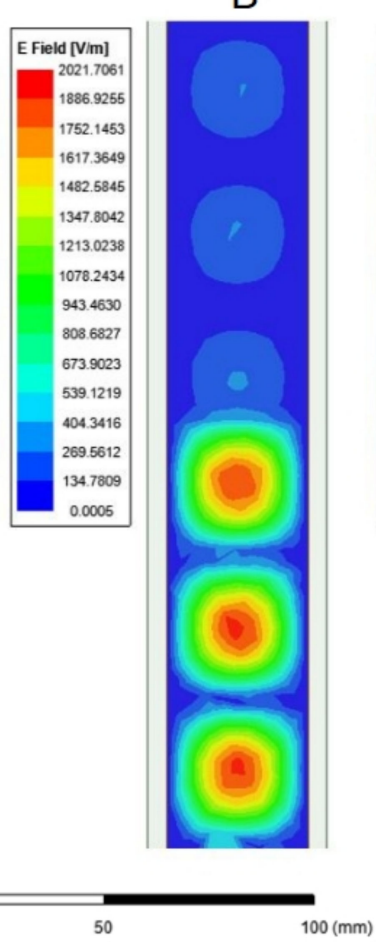

C

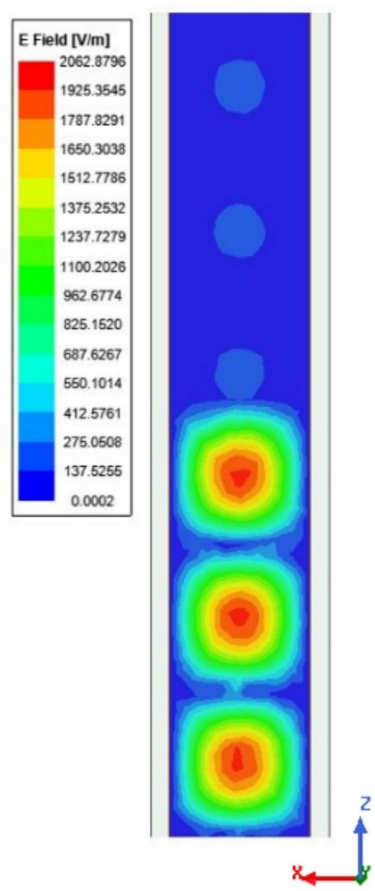

Figure 11. Electric field intensity distribution (ANSYS HFSS) in the WR-137 waveguide fragment, in TE10 mode for $6 \mathrm{GHz}$, in front of and behind a PAN fabric barrier covered with 1 PANI layer (A), 3 PANI layers (B) and 5 PANI layers (C).

A

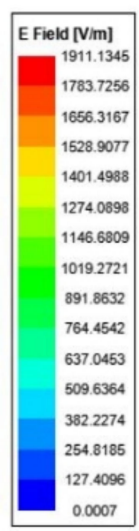

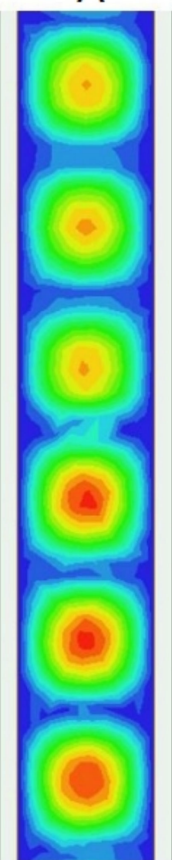
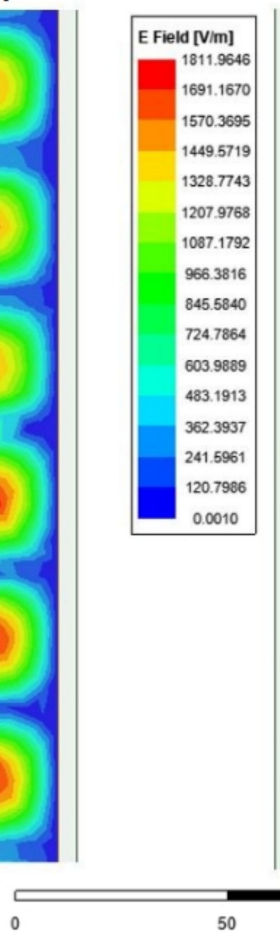

B

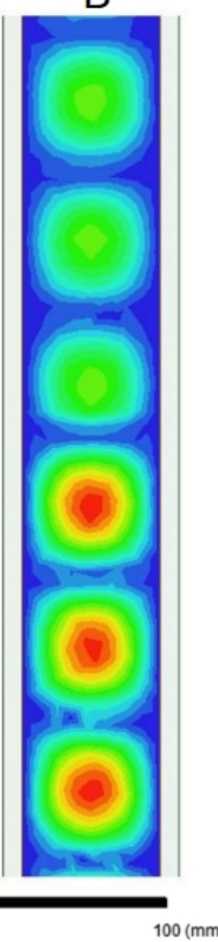

C
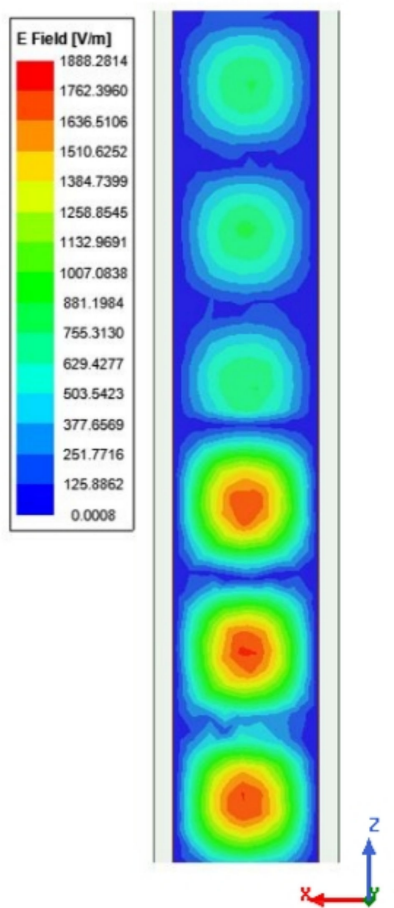

Figure 12. Electric field intensity distribution (ANSYS HFSS) in the WR-137 waveguide fragment, in TE10 mode for $6 \mathrm{GHz}$, in front of and behind a PAN fabric barrier covered with 1 PPy layer (A), 3 PPy layers (B) and 5 layers of PPy (C). 
Figures 13 and 14 show the variability of the transmittance and the reflectance coefficients of shielding samples, respectively for two cases - the results of model tests (solid line) and the results of experimental tests (dotted line). The colors used differentiate the graphs in terms of the number of layers and the conductive polymers used. The results of the experimental studies were discussed in detail in Figures 7 and 8. The results of the model tests were carried out in a virtual measurement environment modeled in the Ansys HFFS environment, based on the diagram shown in Figure 2. The models of textile shielding tests were made on the basis of Figure 3, while their material and electrical parameters were adopted on the basis of Tables 1 and 2.

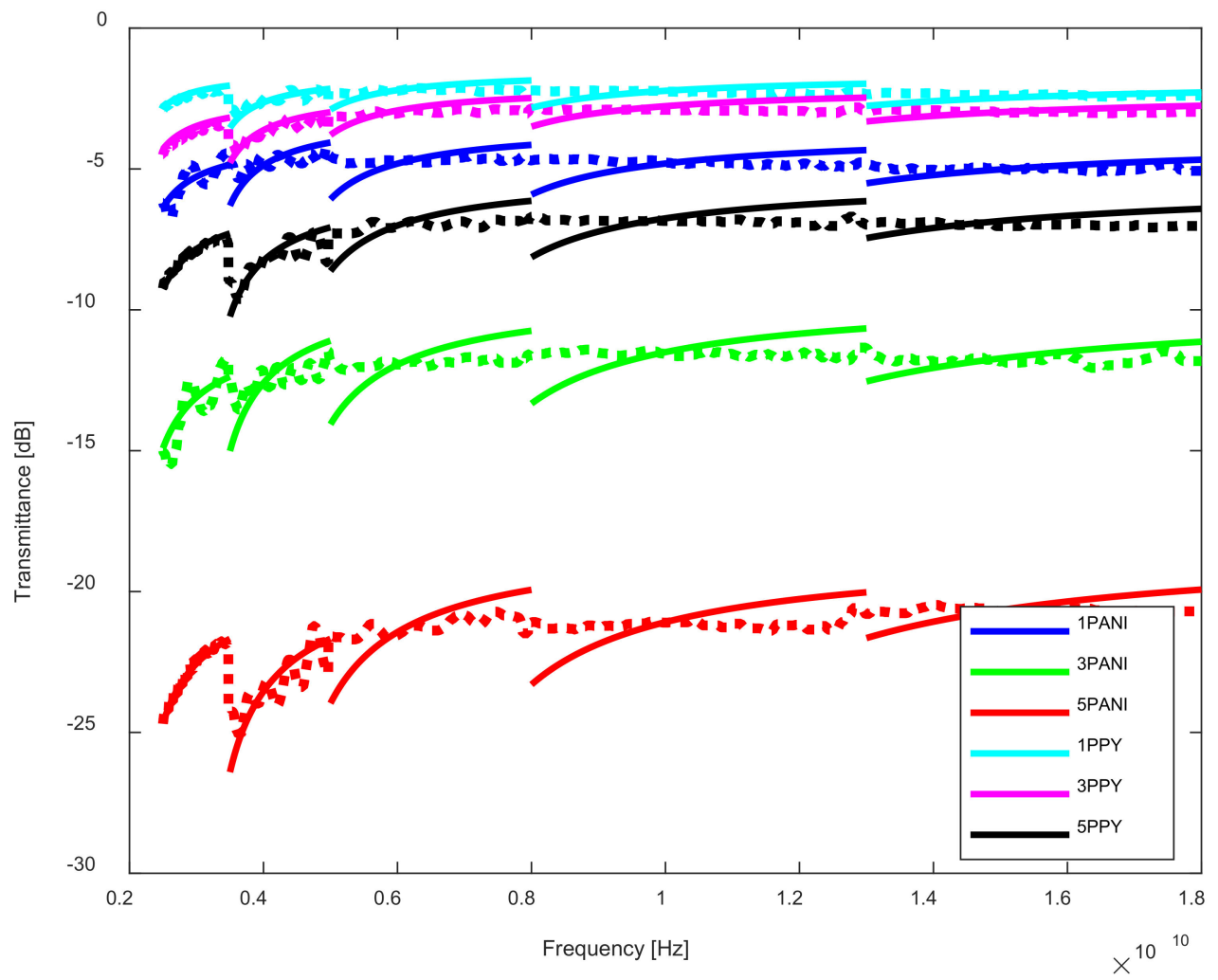

Figure 13. Model waveforms (solid) and measurement results (dotted) of transmittance in the tested frequency range from 2.5 to $18 \mathrm{GHz}$ for textile samples printed with PANI and PPy conductive polymers.

The comparison of the results of model analysis and experimental transmission coefficients presented in Figure 13 shows a relatively good agreement. The model used especially faithfully reproduces the experimental results in the lower frequency ranges (i.e., in the range from 2.5 to $8 \mathrm{GHz}$ ). In the ranges above $8 \mathrm{GHz}$, the compatibility is slightly worse, but the matching error does not exceed a few $\mathrm{dB}$. In higher frequency ranges, the results of model tests are characterized by a discontinuity resulting from the mapped phenomenon of waveguide dispersion. The results of experimental tests reflect relatively poorly the phenomenon of waveguide dispersion (discontinuity at the limit of the waveguide usability), which may be due to the fact that the actual sample of the textile shielding material was characterized by flexibility and low stiffness, which led to slight changes in its geometry in subsequent measurements.

The analysis of Figure 14, which presents the comparison of the reflectance diagrams for the case of model and experimental tests, leads to very similar conclusions as in the case of Figure 13. The best compatibility between the model and experimental waveforms was also obtained for lower frequencies (i.e., from 2.5 to 5 or $8 \mathrm{GHz}$ ). Above this range, from 8 to $18 \mathrm{GHz}$, the compliance is minimally worse, which is influenced by a change 
in the geometry of flexible samples during the measurements and a slightly larger error which is subject to the determination of the reflectance in the actual measuring system.

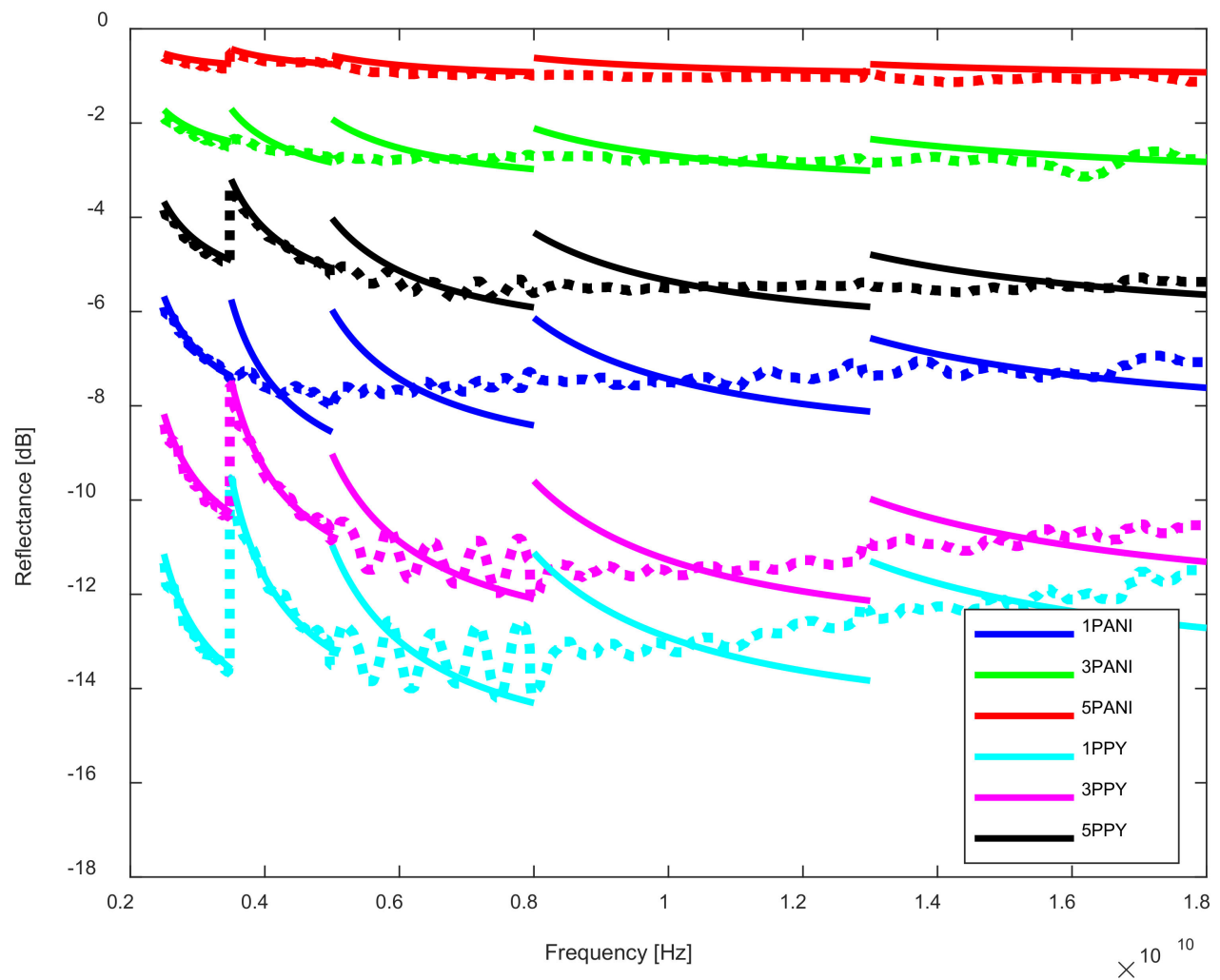

Figure 14. Model waveforms (solid) and measurement results (dotted) of reflectance in the tested frequency range from 2.5 to $18 \mathrm{GHz}$ for textile samples inkjet printed with PANI and PPy conductive polymers.

In order to even better authenticate the good compatibility of the experimental and model waveforms of the transmittance and reflectance presented in Figures 13 and 14, a measure in the form of the MAPE (mean absolute from percentage error) error was proposed. MAPE was expressed by Formulas (7) and (8) separately for the transmittance and reflectance:

$$
\begin{aligned}
& Q_{1}=\frac{100}{401} \sum_{1}^{401}\left|\frac{\bmod \left(T_{\text {data }}\right)-\bmod \left(T_{\text {model }}\right)}{\bmod \left(T_{\text {data }}\right)}\right| \\
& Q_{2}=\frac{100}{401} \sum_{1}^{401}\left|\frac{\bmod \left(R_{\text {data }}\right)-\bmod \left(R_{\text {model }}\right)}{\bmod \left(R_{\text {data }}\right)}\right|
\end{aligned}
$$

where:

$\bmod \left(T_{\text {data }}\right)$ - modulus of measurement transmittance data;

$\bmod \left(T_{\text {model }}\right)$-modulus of model transmittance data;

$\bmod \left(R_{\text {data }}\right)-$ modulus of measurement reflectance data;

$\bmod \left(R_{\text {model }}\right)$-modulus of model reflectance data.

Errors defined by Equations (7) and (8) represent the percentage measure of the distance between the model and experimental curves within each measurement sub-range (401 samples) determined by one type of waveguide used for experimental and model tests. The list of errors is presented in Table 4, while the average value of transmittance and reflectance errors in the entire measuring ranges from 2.5 to $18 \mathrm{GHz}$ is presented in the bar charts in Figure 15. The errors presented in Figure 15 show that the average error of fitting the model and experimental curves of transmittance and reflectance does not exceed $8 \%$, 
but usually it is even lower than $5 \%$. Good compatibility of the model and experimental waveforms is also shown in the tabular data (Table 4), where the errors are divided into individual measuring ranges and half of them do not exceed the value of $5 \%$. It can also be seen that the five-layer samples covered with PANI and PPy polymers are characterized by better compatibility of the model and experimental waveforms, which proves the greater homogeneity of the samples, which is easier to reproduce in the form of a model.

Table 4. List of MAPE (mean absolute of percentage error) errors for all samples of shielding materials in individual measurement ranges: Q1-MAPE of the transmittance factor, Q2-MAPE of the reflectance.

\begin{tabular}{|c|c|c|c|c|c|c|c|c|c|c|c|c|}
\hline \multirow[b]{2}{*}{ Frequency Range } & \multicolumn{2}{|c|}{$\begin{array}{c}\text { 1_PANI } \\
\text { Layer }\end{array}$} & \multicolumn{2}{|c|}{$\begin{array}{c}\text { 3_PANI } \\
\text { Layers }\end{array}$} & \multicolumn{2}{|c|}{$\begin{array}{c}\text { 5_PANI } \\
\text { Layers }\end{array}$} & \multicolumn{2}{|c|}{$\begin{array}{l}\text { 1_PPy } \\
\text { Layer }\end{array}$} & \multicolumn{2}{|c|}{$\begin{array}{l}\text { 3_PPy } \\
\text { Layers }\end{array}$} & \multicolumn{2}{|c|}{$\begin{array}{c}\text { 5_PPy } \\
\text { Layers }\end{array}$} \\
\hline & $\begin{array}{c}\mathrm{Q1} \\
{[\%]}\end{array}$ & $\begin{array}{c}\text { Q2 } \\
{[\%]}\end{array}$ & $\begin{array}{c}\text { Q1 } \\
{[\%]}\end{array}$ & $\begin{array}{c}\text { Q2 } \\
{[\%]}\end{array}$ & $\begin{array}{c}\mathrm{Q} 1 \\
{[\%]}\end{array}$ & $\begin{array}{c}\mathrm{Q} 2 \\
{[\%]}\end{array}$ & $\begin{array}{c}\mathrm{Q1} \\
{[\%]}\end{array}$ & $\begin{array}{c}\mathrm{Q} 2 \\
{[\%]}\end{array}$ & $\begin{array}{c}\mathrm{Q1} \\
{[\%]}\end{array}$ & $\begin{array}{c}\text { Q2 } \\
{[\%]}\end{array}$ & $\begin{array}{c}\mathrm{Q} 1 \\
{[\%]}\end{array}$ & $\begin{array}{c}\text { Q2 } \\
{[\%]}\end{array}$ \\
\hline $2.5-3.5 \mathrm{GHz}$ & 6.405 & 1.038 & 4.165 & 5.545 & 0.740 & 1.369 & 5.076 & 2.092 & 5.740 & 2.109 & 1.515 & 3.405 \\
\hline $3.5-5.0 \mathrm{GHz}$ & 7.529 & 6.541 & 4.935 & 7.427 & 2.398 & 1.885 & 5.710 & 1.098 & 5.190 & 1.070 & 4.276 & 1.779 \\
\hline $5.0-8.0 \mathrm{GHz}$ & 8.013 & 8.189 & 5.693 & 9.013 & 3.258 & 3.203 & 8.968 & 5.729 & 8.980 & 5.150 & 6.782 & 6.187 \\
\hline $8.0-13.0 \mathrm{GHz}$ & 8.428 & 6.856 & 5.512 & 6.421 & 3.422 & 4.056 & 9.987 & 6.329 & 9.652 & 5.622 & 7.067 & 6.767 \\
\hline $13.0-18.0 \mathrm{GHz}$ & 4.173 & 4.121 & 3.115 & 8.218 & 2.212 & 5.679 & 6.324 & 4.834 & 5.357 & 4.186 & 4.722 & 5.057 \\
\hline
\end{tabular}

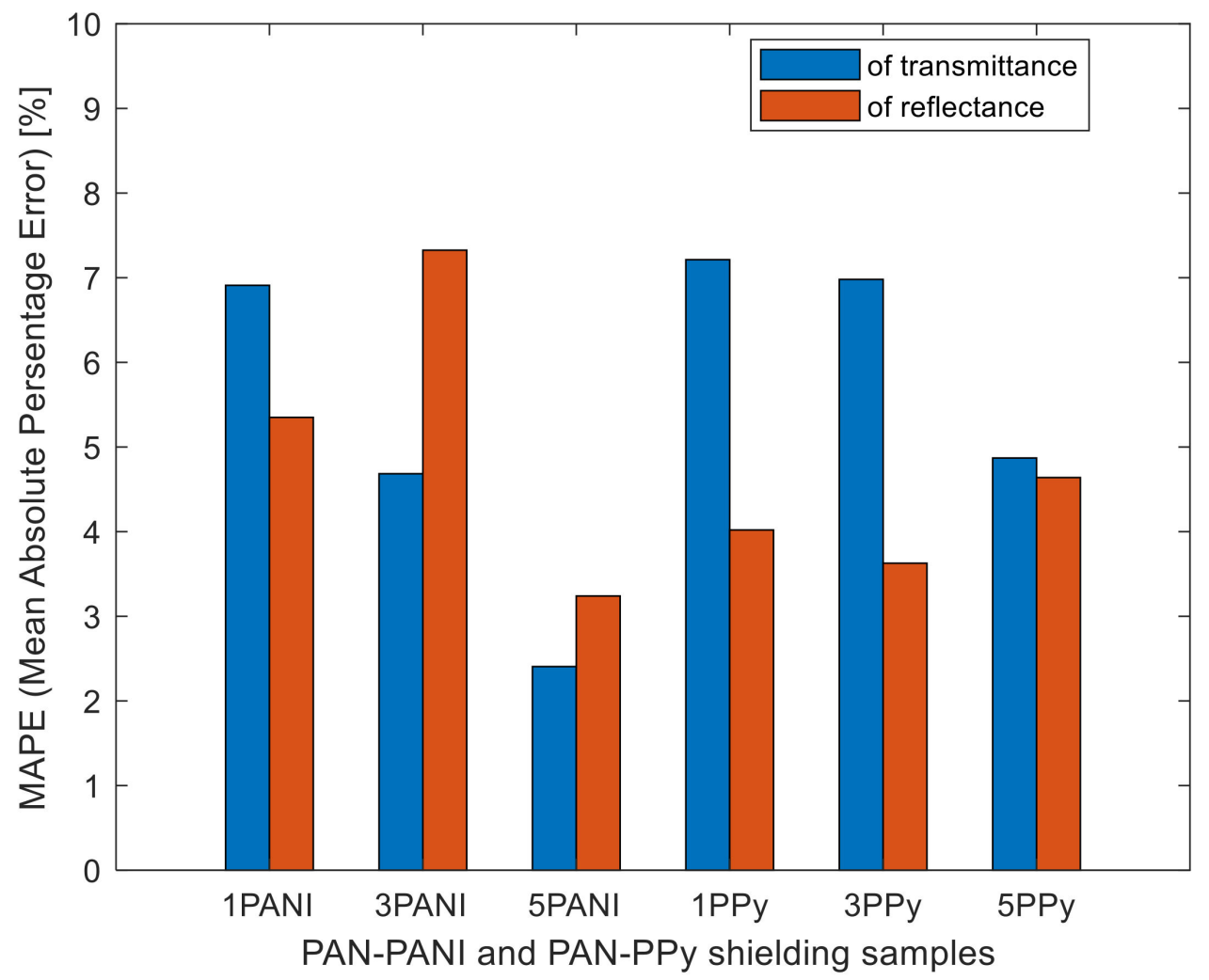

Figure 15. Average value of MAPE errors for the transmittance and reflectance in the entire measuring range from 2.5 to $18 \mathrm{GHz}$.

\section{Conclusions}

Consideration of the contribution of the reflection and absorption components makes sense only when analyzing the shielding effectiveness (SE) simultaneously. On the basis of the [65] standard, the required level of SE should be determined depending on the potential application, and only then should the factors that make up this process be analyzed. For example, with a required shielding level of $>20 \mathrm{~dB}$ (good), (Table 3 shows that it is five 
PANI layers) the reflection and absorption components are $79 \%$ and $20 \%$, respectively. At high values of SE (where the transmission coefficient is $<1 \%$ ), the dominant phenomenon is the reflection of the EM wave, caused by the high conductivity value of the layer which the EM wave hits. At lower values of SE (where, for example, the transmission coefficient is $>10 \%$ ), the content of the absorption coefficient is much higher, which is caused by the interaction of the wave with the material structure and its greater dispersion in the material itself.

SE PPy/PAN is inferior to PANI/PAN structures with the same number of layers due to the differences in conductivity of both polymers.

The amount of electrically conductive polymer (both PANI and PPy) was calculated per $1 \mathrm{~m}^{2}$ of polyacrylonitrile material surface. As can be seen from the data in Table 1, the amount of PPy was relatively lower than the amount of PANI, which results from the estimated molar mass of both polymers. This way, it translates into the screening efficiency (SE), which is better for the PANI/PAN composite than PPy/PAN, with the same number of layers (Table 3 ).

As the number of layers of conductive polymers increases, the reflectance increases both for the PANI/PAN system and the PPy/PAN system. On the other hand, EMF absorption decreases with the increase in the number of PANI layers, and, vice versa, it increases with the number of PPy layers (Table 3). This phenomenon is related to the electrical conductivity of the tests. Table 2 shows the values of the surface resistance of the PANI/PAN and PPy/PAN tests as a function of the number of printed polymer layers. For the PANI/PAN sample, significantly lower surface resistance values were obtained than for the PPy/PANI samples, which proves a better electrical conductivity of polyaniline layers on polyacrylonitrile and thus confirms the high reflectance values for these samples (Table 3).

Modeling with the use of the finite difference method gives good compliance with the experimental results and allows for the design of new shielding materials based on a virtual measuring station.

Author Contributions: Conceptualization, T.R.; investigation, I.K. and T.R.; methodology, T.R., Z.S.; resources, T.R., Z.S.; supervision, Z.S.; visualization, T.R., I.K.; writing, T.R., I.K.; writing-review and editing, T.R., Z.S., I.K. All authors have read and agreed to the published version of the manuscript.

Funding: This research received no external funding.

Institutional Review Board Statement: Not applicable.

Informed Consent Statement: Not applicable.

Data Availability Statement: The data are not publicly available due to the privacy.

Conflicts of Interest: The authors declare not competing interests.

\section{References}

1. Aphesteguy, J.C.; Damiani, A.; DiGiovanni, D.; Jacobo, S.E. Microwave absorption behavior of a polyaniline magnetic composite in the X-band. Phys. B Condens. Matter 2012, 407, 3168-3171. [CrossRef]

2. Aphesteguy, J.C.; Damiani, A.; DiGiovanni, D.; Jacobo, S.E. Microwave-absorbing characteristics of epoxy resin composites containing nanoparticles of NiZn- and NiCuZn-ferrites. Phys. B Condens. Matter 2009, 404, 2713-2716. [CrossRef]

3. Ohlan, A.; Singh, K.; Chandra, A.; Dhawan, S.K. Microwave absorption properties of conducting polymer composite with barium ferrite nanoparticles in 12.4-18 GHz. Appl. Phys. Lett. 2008, 93, 053114. [CrossRef]

4. Wen, H.; Cao, M.; Sun, G.; Xu, W.; Wang, D.; Zhang, X.; Hu, C. Hierarchical Three-Dimensional Cobalt Phosphate Microarchitectures: Large-Scale Solvothermal Synthesis, Characterization, and Magnetic and Microwave Absorption Properties. J. Phys. Chem. C 2008, 112, 15948-15955. [CrossRef]

5. Das, C.K.; Mandal, A. Microwave Absorbing Properties of DBSA-doped Polyaniline/ $\mathrm{BaTiO}_{3}-\mathrm{Ni}_{0.5} \mathrm{Zn}_{0.5} \mathrm{Fe}_{2} \mathrm{O}_{4} \mathrm{Nanocomposites}_{\text {. J }}$. Mater. Sci. Res. 2012, 1, 1. [CrossRef]

6. Colaneri, N.F.; Schacklette, L.W. EMI shielding measurements of conductive polymer blends. IEEE Trans. Instrum. Meas. 1992, 41, 291-297. [CrossRef]

7. Lin, M.-S.; Chen, C.H. Plane-wave shielding characteristics of anisotropic laminated composites. IEEE Trans. Electromagn. Compat. 1993, 35, 21-27. [CrossRef] 
8. Naishadham, K. Shielding effectiveness of conductive polymers. IEEE Trans. Electromagn. Compat. 1992, 34, 47-50. [CrossRef]

9. Saib, A.; Bednarz, L.; Daussin, R.; Bailly, C.; Lou, X.; Thomassin, J.-M.; Pagnoulle, C.; Detrembleur, C.; Jerome, R.; Huynen, I. Carbon nanotube composites for broadband microwave absorbing materials. IEEE Trans. Microw. Theory Tech. 2006, 54, 2745-2754. [CrossRef]

10. Villacorta, B.S.; Ogale, A.A.; Hubing, T.H. Effect of heat treatment of carbon nanofibers on the electromagnetic shielding effectiveness of linear low density polyethylene nanocomposites. Polym. Eng. Sci. 2013, 53, 417-423. [CrossRef]

11. Saini, P.; Aror, M. Microwave Absorption and EMI Shielding Behavior of Nanocomposites Based on Intrinsically Conducting Polymers, Graphene and Carbon Nanotubes. In New Polymers for Special Applications; InTech: London, UK, 2012. [CrossRef]

12. Saini, P.; Choudhary, V.; Singh, B.P.; Mathur, R.B.; Dhawan, S.K. Enhanced microwave absorption behavior of polyanilineCNT/polystyrene blend in 12.4-18.0 GHz range. Synth. Met. 2011, 161, 1522-1526. [CrossRef]

13. Hoang, N.H.; Wojkiewicz, J.-L.; Miane, J.-L.; Biscarro, R.S. Lightweight electromagnetic shields using optimized polyaniline composites in the microwave band. Polym. Adv. Technol. 2007, 18, 257-262. [CrossRef]

14. Saini, P.; Choudhary, V.; Singh, B.P.; Mathur, R.B.; Dhawan, S.K. Polyaniline-MWCNT nanocomposites for microwave absorption and EMI shielding. Mater. Chem. Phys. 2009, 113, 919-926. [CrossRef]

15. Wang, Y.; Jing, X. Intrinsically conducting polymers for electromagnetic interference shielding. Polym. Adv. Technol. 2005, 16, 344-351. [CrossRef]

16. Kim, M.S.; Kim, H.K.; Byun, S.W.; Jeong, S.H.; Hong, Y.K.; Joo, J.S.; Song, K.T.; Kim, J.K.; Lee, C.J.; Lee, J.Y. PET fabric/polypyrrole composite with high electrical conductivity for EMI shielding. Synth. Met. 2002, 126, 233-239. [CrossRef]

17. Kaynak, A.; Håkansson, E.; Amiet, A. The influence of polymerization time and dopant concentration on the absorption of microwave radiation in conducting polypyrrole coated textiles. Synth. Met. 2009, 159, 1373-1380. [CrossRef]

18. Saini, P.; Choudhary, V.; Dhawan, S.K. Improved microwave absorption and electrostatic charge dissipation efficiencies of conducting polymer grafted fabrics prepared via in situ polymerization. Polym. Adv. Technol. 2012, 23, 343-349. [CrossRef]

19. Zhu, X.; Li, X. Current status and research direction of electromagnetic shielding fabric. In Proceedings of the $2011 \mathrm{Cross}$ Strait Quad-Regional Radio Science and Wireless Technology Conference, Harbin, China, 26-30 July 2011; IEEE: Piscataway, NJ, USA, 2011; pp. 104-107.

20. Saini, P.; Choudhary, V. Conducting polymer coated textile based multilayered shields for suppression of microwave radiations in 8.2-12.4 GHz range. J. Appl. Polym. Sci. 2013, 129, 2832-2839. [CrossRef]

21. Dhawan, S.; Singh, N.; Venkatachalam, S. Shielding behaviour of conducting polymer-coated fabrics in X-band, W-band and radio frequency range. Synth. Met. 2002, 129, 261-267. [CrossRef]

22. Muthukumar, N.; Thilagavathi, G. Development and characterization of electrically conductive polyaniline coated fabrics. Indian J. Chem. Technol. 2012, 19, 434-441.

23. Håkansson, E.; Amiet, A.; Kaynak, A. Electromagnetic shielding properties of polypyrrole/polyester composites in the 1-18 GHz frequency range. Synth. Met. 2006, 156, 917-925. [CrossRef]

24. Wojkiewicz, J.-L.; Fauveaux, S.; Miane, J.-L. Electromagnetic shielding properties of polyaniline composites. Synth. Met. 2003, 135-136, 127-128. [CrossRef]

25. Engin, F.Z.; Usta, I. Electromagnetic shielding effectiveness of polyester fabrics with polyaniline deposition. Text. Res. J. 2014, 84, 903-912. [CrossRef]

26. Saini, P.; Choudhary, V. Electrostatic charge dissipation and electromaghetic interference shielding response of polyaniline based conducting fabrics. Indian J. Pure Appl. Phys. 2013, 51, 112-117.

27. Folgueras, L.d.C.; Nohara, E.L.; Faez, R.; Rezende, M.C. Dielectric microwave absorbing material processed by impregnation of carbon fiber fabric with polyaniline. Mater. Res. 2007, 10, 95-99. [CrossRef]

28. Phang, S.W.; Tadokoro, M.; Watanabe, J.; Kuramoto, N. Microwave absorption behaviors of polyaniline nanocomposites containing $\mathrm{TiO}_{2}$ nanoparticles. Curr. Appl. Phys. 2008, 8, 391-394. [CrossRef]

29. Stejskal, J.; Gilbert, R.G. Polyaniline. Preparation of a conducting polymer (IUPAC Technical Report). Pure Appl. Chem. 2002, 74, 857-867. [CrossRef]

30. MacDiarmid, A.G.; Epstein, A.J. Secondary doping in polyaniline. Synth. Met. 1995, 69, 85-92. [CrossRef]

31. Stempien, Z.; Rybicki, T.; Rybicki, E.; Kozanecki, M.; Szynkowska, M.I. In-situ deposition of polyaniline and polypyrrole electroconductive layers on textile surfaces by the reactive ink-jet printing technique. Synth. Met. 2015, 202, 49-62. [CrossRef]

32. Dhawan, S.; Singh, N.; Venkatachalam, S. Shielding effectiveness of conducting polyaniline coated fabrics at $101 \mathrm{GHz}$. Synth. Met. 2001, 125, 389-393. [CrossRef]

33. Bhadra, S.; Khastgir, D.; Singha, N.K.; Lee, J.H. Progress in preparation, processing and applications of polyaniline. Prog. Polym. Sci. 2009, 34, 783-810. [CrossRef]

34. Kim, B.; Koncar, V.; Devaux, E.; Dufour, C.; Viallier, P. Electrical and morphological properties of PP and PET conductive polymer fibers. Synth. Met. 2004, 146, 167-174. [CrossRef]

35. Foroughi, J.; Spinks, G.M.; Wallace, G.G. Conducting Polymer Fibers. In Handbook of Smart Textiles; Springer: Singapore, 2014; pp. 1-27.

36. Knittel, D.; Schollmeyer, E. Electrically high-conductive textiles. Synth. Met. 2009, 159, 1433-1437. [CrossRef]

37. Loffredo, F.; Burrasca, G.; Quercia, L.; Sala, D.D. Gas Sensor Devices Obtained by Ink-jet Printing of Polyaniline Suspensions. Macromol. Symp. 2007, 247, 357-363. [CrossRef] 
38. De Gans, B.-J.; Duineveld, P.C.; Schubert, U.S. Inkjet Printing of Polymers: State of the Art and Future Developments. Adv. Mater. 2004, 16, 203-213. [CrossRef]

39. Tekin, E.; de Gans, B.-J.; Schubert, U.S. Ink-jet printing of polymers? From single dots to thin film libraries. J. Mater. Chem. 2004, 14, 2627. [CrossRef]

40. Bietsch, A.; Zhang, J.; Hegner, M.; Lang, H.P.; Gerber, C. Rapid functionalization of cantilever array sensors by inkjet printing. Nanotechnology 2004, 15, 873-880. [CrossRef]

41. Perumalraj, R.; Dasaradan, B.S. Electromagnetic Shielding Effectiveness of Doubled Copper-Cotton Yarn Woven Materials. Fibres Text. East. Eur. 2010, 18, 74-80.

42. Neruda, M.; Vojtech, L. Electromagnetic Shielding Effectiveness of Woven Fabrics with High Electrical Conductivity: Complete Derivation and Verification of Analytical Model. Materials 2018, 11, 1657. [CrossRef]

43. Rybicki, T. EMI Shielding and Reflection From Textile Mesh Grids Compared With Analytic Models. IEEE Trans. Electromagn. Compat. 2019, 61, 372-380. [CrossRef]

44. Radulescu, I.R.; Surdu, L.; Scarlat, R.; Constantin, C.; Mitu, B.; Morarr, C.; Costea, M. Modelling the woven structures with inserted conductive yarns coated with magnetron plasma and testing their shieldning effectiveness. Textiles 2021, 1, 4-20. [CrossRef]

45. Al Achkar, G.; Pichon, L.; Daniel, L.; Benjelloun, N. Effective Electromagnetic Properties of Woven Fiber Composites for Shielding Applications. IEEE Trans. Electromagn. Compat. 2020, 62, 1082-1089. [CrossRef]

46. Taflowe, A.; Hagness, S.C. Computational Electrodynamics: The Finite-Difference Time-Domain Method, 3rd ed.; Artech House: Norwood, MA, USA, 2005.

47. Liu, Z.; Su, Y.; Li, Y.; Pan, Z.; Wang, X. Numerical calculation of shielding effectiveness of electromagnetic shielding fabric based on finite difference time domain. Int. J. Appl. Electromagn. Mech. 2016, 50, 593-603. [CrossRef]

48. Kubík, Z.; Skála, J. Shielding Effectiveness Simulation of Small Perforated Shielding Enclosures Using FEM. Energies 2016, 9, 129. [CrossRef]

49. Harrington, R.F. IEEE/OUP Series on Electromagnetic Wave Theory; Oxford University Press: Oxford, UK, 1993.

50. Slovenski Inštitut za Standardizacijo. EN 12127. Textiles_Fabrics_Determination of Mass Per Unit Area Using Small Samples; Slovenski Inštitut za Standardizacijo: Ljubljana, Slovenia, 1997.

51. Slovenski Inštitut za Standardizacijo. EN 1049-2. Textiles—Woven Fabrics—Construction—Methods of Analysis—Part 2: Determination of Number of Threads Per Unit Length; Slovenski Inštitut za Standardizacijo: Ljubljana, Slovenia, 1993.

52. Van der Pauw, L.J. A method of measuring the resistivity and Hall coefficient on lamellae of arbitrary shape. Philips Tech. Rev. 1958, 20, 220-224.

53. Tokarska, M. Characterization of electro-conductive textile materials by its biaxial anisotropy coefficient and resistivity. J. Mater. Sci. Mater. Electron. 2019, 30, 4093-4103. [CrossRef]

54. Tokarska, M. New concept in assessing compactness of woven structure in terms of its resistivity. J. Mater. Sci. Mater. Electron. 2016, 27, 7335-7341. [CrossRef]

55. Rybicki, T.; Stempień, Z.; Rybicki, E.; Szugajew, L. EMI Shielding Effectiveness of Polyacrylonitrile Fabric with Polyaniline Deposition by Reactive Ink-Jet Printing and Model Approach. IEEE Trans. Electromagn. Compat. 2016, 58, 1025-1032. [CrossRef]

56. Casey, K.F. Electromagnetic shielding behavior of wire-mesh screens. IEEE Trans. Electromagn. Compat. 1988, 30, 298-306. [CrossRef]

57. Ilvinas Kancleris, Ž.; Slekas, G.; Matulis, A. Modeling of Two-Dimensional Electron Gas Sheet in FDTD Method. IEEE Trans. Antennas Propag. 2013, 61, 994-996. [CrossRef]

58. Rubeziene, V.; Baltusnikaite-Guzaitiene, J.; Abraitiene, A.; Sankauskaite, A.; Ragulis, P.; Santos, G.; Pimenta, J. Development and investigation of PEDOT-PSS composition coated fabrics intended for microwave shielding and absorption. Polymers 2021, 13, 1191. [CrossRef] [PubMed]

59. Orfandis, S.J. Electromagnetic Waves and Antennas; Rutgers University: New Brunswick, NJ, USA, 2002.

60. Brown, L.P.; Long, A.C. Modeling the geometry of textile reinforcements for composites: TexGen. In Composite Reinforcements for Optimum Performance; Woodhead Publishing: Sawston, UK, 2011; pp. 239-264.

61. Lin, H.; Brown, L.P.; Long, A.C. Modelling and Simulating Textile Structures Using TexGen. Adv. Mater. Res. 2011, 331, 44-47. [CrossRef]

62. Diaz, A.F.; Castillo, J.I.; Logan, J.A.; Lee, W.-Y. Electrochemistry of conducting polypyrrole films. J. Electroanal. Chem. Interfacial Electrochem. 1981, 129, 115-132. [CrossRef]

63. López Cascales, J.J.; Otero, T.F. Molecular dynamic simulation of the hydration and diffusion of chloride ions from bulk water to polypyrrole matrix. J. Chem. Phys. 2004, 120, 1951-1957. [CrossRef] [PubMed]

64. Paul, C.R. Introduction to Electromagnetic Compatibility; Wiley Series in Microwave and Optical Engineering; Wiley: Hoboken, NJ, USA, 2006; ISBN 9780471758143.

65. Specified Requirements of Electromagnetic Shielding Textiles FTTS-FA-003. Available online: https://www.ftts.org.tw/images/ 003e.pdf (accessed on 28 April 2021). 